\title{
Cantorian-Fractal Kinetic Energy and Potential Energy as the Ordinary and Dark Energy Density of the Cosmos Respectively
}

\author{
Mohamed S. El Naschie \\ Department of Physics, Faculty of Science, University of Alexandria, Alexandria, Egypt \\ Email: Chaossf@aol.com
}

How to cite this paper: El Naschie, M.S. (2016) Cantorian-Fractal Kinetic Energy and Potential Energy as the Ordinary and Dark Energy Density of the Cosmos Respectively. Natural Science, 8, 511-540. http://dx.doi.org/10.4236/ns.2016.812052

Received: November 23, 2016 Accepted: November 29, 2016

Published: December 2, 2016

Copyright $\odot 2016$ by author and Scientific Research Publishing Inc. This work is licensed under the Creative Commons Attribution International License (CC BY 4.0). http://creativecommons.org/licenses/by/4.0/ (c) (i) Open Access

\section{Abstract}

In a one-dimension Mauldin-Williams Random Cantor Set Universe, the Sigalotti topological speed of light is $c=\phi$ where $\phi=(\sqrt{5}-1) / 2$. It follows then that the corresponding topological acceleration must be a golden mean downscaling of $c$ namely $g=(c)(\phi)=\phi^{2}$. Since the maximal height in the one-dimensional universe must be $\ell / 2=1 / 2$ where $\ell$ is the unit interval length and note that the topological mass $(m)$ and topological dimension $(D)$ where $m=D=5$ are that of the largest unit sphere volume, we can conclude that the potential energy of classical mechanics $E_{p}=m g(\ell / 2)$ translates to $E_{p}($ Topological $)=(5)\left(\phi^{2}\right) / 2$. Remembering that the kinetic energy is $E_{K}=\frac{1}{2} m v^{2}$, then by the same logic we see that $E_{K}($ Topological $)=$ $\frac{1}{2} \phi^{3}(\phi)^{2}=\phi^{5} / 2$ when $m=5$ is replaced by $\phi^{3}$ for reasons which are explained in the main body of the present work. Adding both expressions together, we find Einstein's maximal energy $E($ Total $)=\left[\left(\phi^{5} / 2\right)+\left(5 \phi^{5} / 2\right)\right] m c^{2}=m c^{2}$. As a general conclusion, we note that within high energy cosmology, the sharp distinction between potential energy and kinetic energy of classical mechanics is blurred on the cosmic scale. Apart of being an original contribution, the article presents an almost complete bibliography on the Cantorian-fractal spacetime theory.

\section{Keywords}

Potential Dark Energy, Kinetic Ordinary Energy, Motion as Illusion, Zenonparadoxa, E-Infinity Theory, Noncommutative Geometry, Topological Acceleration, Cantorian Universe, Accelerated Cosmic Expansion 


\section{Introduction}

Space, time, matter and energy are concepts far from being trivial or obvious even within Newtonian classical mechanics [1]-[6]. This view was amply confirmed and deeply pondered in the wonderful writing of scientists such as H. Weyl and Max Jammar [1] [3]. Starting more or less from there it became the Author's lifelong work and even magical fascination to incorporate the basic structure of quantum mechanics into the very topology and geometry of space and time [7]-[428]. To do this, the author followed a path inspired by the work of Richard Feynman and its development by the Canadian Physicist G. Ord and French Astrophysicist L. Nottale [7] [12] [13].

The crucial turning point for E-infinity was when the Author's basic work came in touch with the work on non-commutative geometry [14] [74]. In particular the superb analysis which the great French mathematician Alain Connes undertook on Penrose's Fractal Tiling Universe using Von-Neumann's pointless geometry [14] [140] is in retrospect the most important central piece in our current understanding of high energy physics and cosmology [7]-[270]. It turned out that the bijection formula which relates the Hausdorff dimension of an $n$-dimensional Cantor manifold to its topological dimension $n[7]$

$$
d_{c}^{(n)}=(1 / \phi)^{n-1}
$$

where $\phi=(\sqrt{5}-1) / 2$ is just a compact version of Von-Neumann-Connes' dimensional function of a Penrose tiling universe [7] [14] [165].

$$
D=a+b \phi ; a, b \in z
$$

In addition this dimensional function is generic and can be used to understand some of the most complex and difficult problems in Physics and Astrophysics [9]-[429]. In particular, it is easily shown using the above that the quantum particle may be described by the zero set as given by the bi-dimension [7] [27]

$$
D(0)=(1 / \phi)^{-1}=(0, \phi)
$$

while the quantum wave maybe modeled by the empty set given by the bi-dimension [7] [27]

$$
D(-1)=(1 / \phi)^{-2}=\left(-1, \phi^{2}\right)
$$

In other words, the zero set quantum particle is described by a bi-dimension, zero for the topological dimension and $\phi$ for the Hausdorff dimension. On the other hand, the empty set quantum wave is fixed by the bi-dimension minus one for the topological dimension and $\phi^{2}$ for the Hausdorff dimension [7] [9] [73].

From this simple mental and mathematical picture, we were able to show that the volume of the quantum particle zero set in Kaluza-Klein spacetime is simply $\phi^{5}$, while the corresponding volume of the quantum wave is $5 \phi^{2}$ [23] [24]. In other words, the measure of the particle is multiplicative while understandably the surface of this volume is a hyper-surface constituting the additive measure of the quantum wave. Since particle and wave in this picture, which is a ball, have a hyper spherical border and are 
therefore necessarily inseparable, it follows then that the total volume of the wave particle "quantum" structure is simply the sum $\phi^{5}+5 \phi^{2}=2$. Inserting in Newton's kinetic energy one finds [137] [138] [139]

$$
E_{K}=\frac{1}{2}\left(\phi^{5}+5 \phi^{2}\right)(m)(v \rightarrow c)^{2}
$$

where $c$ is the speed of light. In that way, we were able to show that [48]-[400]

$$
E_{K} \rightarrow E=\left(\frac{1}{2}\right)(2) m c^{2}=m c^{2}=E(\text { Einstein }) .
$$

By contrast in the present work, we will take another route to arrive at the same result by stressing an optional separation between kinetic energy and potential energy in fractal spacetime.

\section{Fractal Potential Energy and Fractal Kinetic Energy of Quantum Spacetime}

The following is a "post-modern" and quite novel approach to the same fundamental problems connected to the total accepted theoretical energy density of the universe versus that which was measured and which gave rise to the new concepts of dark energy and dark matter. This problem was previously solved using a plethora of mathematical techniques. However and as we anticipated in the previous section, we are making in the present analysis a strict although optional distinction between potential energy and kinetic energy [430].

For this reason we start from a one-dimensional Cantor set. For this set everything is zero with the exception of one fundamental thing. The bi-dimension indicated already that the topological dimension is zero. The only thing which is not zero is the Hausdorff dimension which is equal to $\phi$, but what about where $\phi$ is embedded? That means where is the nothingness which is left from removing iteratively but randomly parts of the unit interval? This zero set "nothing" is not really nothing but rather something and is embedded in the $\phi$ complementary empty set. Since the dimension of the unit interval is $D=1$, then the dimension of this complementary empty set must be a trivial $1-\phi=\phi^{2}$. This agrees perfectly with the bijection formula and the dimensional function for $n=-1$ which gives [154] [155]

$$
d_{c}^{(-1)}=(1 / \phi)^{-2}=\phi^{2}
$$

or equivalently

$$
D(-1) \equiv\left(-1, \phi^{2}\right)
$$

In addition the measure i.e. the length of the complementary set is a trivial $1-0=1$. In other words this empty set is a fat Cantor set [7] [154] [155].

Now let us look at the velocity in $D(0)$. This was established by the work of the notable Italian physicist $L$. Sigalotti to be $c=\phi$ which is not surprisingly the only non-zero quantity in the Cantor set. Next we like to determine the acceleration corresponding to $V$ or say the acceleration analogous to Newtonian gravity on earth. 
Now in E-Infinity we have a technique similar to non standard analysis were differentiation is equivalent to golden mean down scaling while integration is a golden mean scaling up [7] [9] [21] [28].

In this case we have to down scale $v \rightarrow c$ by multiplication with $\phi$. Therefore the acceleration is simply

$$
g=(v \rightarrow c)(\phi)=(\phi)(\phi)=\phi^{2} .
$$

Again, not surprisingly this corresponds in elasticity to a torsional term and is numerically equal to the Hausdorff dimension of the empty set quantum wave [19] [28] [119].

Our next step is to determine the height of the mass in the gravity field which is endowed with a positive energy i.e. a potential energy. Since the edges of the unit Cantor interval corresponding to the limit of the universe at a nominal infinity, then the maximum length of the unit interval is simply one half $(1 / 2)$.

Now we can write heuristically a fractal expression for conventional potential energy for $h=\ell / 2=1 / 2$

$$
E_{p}=m g h=(m)\left(\phi^{2}\right) / 2
$$

provided we know what $m$ is. This is easily reasoned if we get access or an insight into the real meaning of mass. This is clearly connected to energy and energy is related to entropy. On the other hand entropy maybe measured via the Hausdorff dimension which is $\phi^{2}$ for the empty set. Now a mass in 5-dimensional spacetime becomes a Kaluza-Klein spacetime five dimensional mass. Consequently, our empty set mass cannot be $(1)^{5}$ which is nothing but 1 . Therefore it must be $m=(1)$ (5). Inserting in to $E_{p}$, we find the familiar expression of ordinary cosmic energy density

$$
\gamma_{(0)}=m g h=5 \phi^{5} / 2
$$

exactly as shown previously using various other methods. Let us stress this point again. We have just established the potential energy nature of dark energy and squared it with the energy of the quantum particle via a mathematical tautology. This is because at the end of the day it is completely the same thing to say

$$
\gamma(D)=(\mathrm{vol}) / 2=\left(5 \phi^{2}\right) / 2
$$

or to say

$$
\gamma(D)=(5)\left(\phi^{2}\right) / 2 \text {. }
$$

Thus $5 \phi^{2}$ could be interpreted as topological empty set mass $m=5$ multiplied with the acceleration $\phi^{2}$ or as the volume of the 5D quantum wave empty set namely the additive volume $5 \phi^{2}$. In other words we have a different mental picture leading to the same result [212] [426].

Returning to the kinetic energy, this is relatively simpler because real energy of real zero set quantum particles is sensibly interpreted as a $3 \mathrm{D}$ mass. In this case we have then $\phi$ to the power of 3D which give us $\phi^{3}$ as a multiplicative 3D mass i.e. volume. 
In turn this can be interpreted as the inverse of the spacetime core Hausdorff dimension [7] [9]

$$
\frac{1}{D}=\frac{1}{4+\phi^{3}}=\phi^{3}
$$

Inserting in Newton's Kinetic energy, we find the expected result

$$
\gamma_{K}=\frac{1}{2} m(v \rightarrow c)^{2}=\left(\frac{1}{2}\right)\left(\phi^{3}\right)(\phi)^{2}=\phi^{5} / 2 .
$$

In agreement with expectations, the total energy which is the sum of the Kinetic and the potential energy is equal to Einstein's maximal energy density [426] [427]

$$
E(\text { Total })=\left(\gamma_{p}+\gamma_{k}\right) m c^{2}=\left(\frac{5 \phi^{2}}{2}+\frac{\phi^{5}}{2}\right) m c^{2}=m c^{2} .
$$

In concluding this part of our analysis we stress the subtlety of various interpretations of $E(D)$ which could be potentially confusing. This is because $5 \phi^{2} / 2$ could be interpreted in equal measure as the quantum wave kinetic energy $E(D)=\left(\frac{1}{2}\right)(m=5)(v=\phi)^{2}$ or the spacetime potential energy $E(D)=m g h=(5)(\phi \phi)(1 / 2)$. In both cases the result is the same but the "pictures" are different. In fact we could go as far as claiming that within quantum cosmology the difference between kinetic energy and potential energy is fuzzy and so is the difference between the state of motion or being at rest which resonates with the old philosophy of Zeno [430].

\section{Conclusion}

We have come a long way in a relatively short time to recognize the depth and beauty involved in the discovery of the so-called missing dark energy of the cosmos. Dark energy is simply potential energy latent in the five-dimensional empty set spacetime. However, one could equally say that dark energy is the energy of quantum wave. Since it may be seen as a product of minus one dimensional empty set, it has a different sign to that of the ordinary energy. Consequently, the topological acceleration $\phi^{2}$ when multiplied with the Kaluza-Klein topological mass and divided by the "height" $1 / 2$ is the cause behind the accelerated expansion of the cosmos. As such our result reinforces recent exciting work reported in [424] [430], and [429] [430]. However the mathematics and methodology used here are entirely different from the said references and therefore this agreement lends both theories considerable credibility.

\section{References}

[1] Weyl, H. (1918) Raum, Zeit, Materie. Vol. 7, Springer, Berlin.

[2] Weyl, H. (1922) Space-Time-Matter. 4th Addition, Dover Publication, Dutton.

[3] Jammer, M. (1993) Concepts of Space. Dover Publication, Mineola.

[4] Jammer, M. (1974) Concept of Force. Recherche, 5, 221-230.

[5] Jammer, M. (1961) Concepts of Mass in Classical and Modern Physics. Dover, New York. 
[6] Jammer, M. (1966) The Conceptual Development of Quantum Mechanics. McGraw-Hill, New York, 399 p.

[7] El Naschie, M.S. (2004) A Review of E Infinity Theory and the Mass Spectrum of High Energy Particle Physics. Chaos, Solitons \& Fractals, 19, 209-236.

https://doi.org/10.1016/S0960-0779(03)00278-9

[8] El Naschie, M.S. (1995) Quantum Mechanics, Diffusion and Chaotic Fractals. Chaos, Solitons \& Fractals, 4, 1235-1247. https://doi.org/10.1016/0960-0779(94)90034-5

[9] El Naschie, M.S. (2009) The Theory of Cantorian Spacetime and High Energy Particle Physics (an Informal Review). Chaos, Solitons \& Fractals, 41, 2635-2646.

https://doi.org/10.1016/j.chaos.2008.09.059

[10] El Naschie, M.S. (2006) Elementary Prerequisites for e-Infinity: (Recommended Background Readings in Nonlinear Dynamics, Geometry and Topology). Chaos, Solitons \& Fractals, 30, 579-605. https://doi.org/10.1016/j.chaos.2006.03.030

[11] El Naschie, M.S. (2006) On an Eleven Dimensional E-Infinity Fractal Spacetime Theory. International Journal of Nonlinear Sciences and Numerical Simulation, 7, 407-409.

[12] El Naschie, M.S. (2007) A Review of Applications and Results of E-Infinity Theory. International Journal of Nonlinear Sciences and Numerical Simulation, 8, 11-20. https://doi.org/10.1515/ijnsns.2007.8.1.11

[13] El Naschie, M.S. (2005) Einstein's Dream and Fractal Geometry. Chaos, Solitons \& Fractals, 24, 1-5. https://doi.org/10.1016/j.chaos.2004.09.001

[14] El Naschie, M.S. (1998) Penrose Universe and Cantorian Spacetime as a Model for Noncommutative Quantum Geometry. Chaos, Solitons \& Fractals, 9, 931-933. https://doi.org/10.1016/S0960-0779(98)00077-0

[15] El Naschie, M.S. (2006) The Idealized Quantum Two-Slit Gedanken Experiment Revisited-Criticism and Reinterpretation. Chaos, Solitons \& Fractals, 27, 843-849. https://doi.org/10.1016/j.chaos.2005.06.002

[16] El Naschie, M.S. (1997) A Note on Quantum Gravity and Cantorian Spacetime. Chaos, Solitons \& Fractals, 8, 131-133. https://doi.org/10.1016/S0960-0779(96)00128-2

[17] El Naschie, M.S. (1994) Is Quantum Space a Random Cantor Set with a Golden Mean Dimension at the Core? Chaos, Solitons \& Fractals, 4, 177-179. https://doi.org/10.1016/0960-0779(94)90141-4

[18] El Naschie, M.S. (1996) Time Symmetry Breaking, Duality and Cantorian Space-Time. Chaos, Solitons \& Fractals, 7, 499-518. https://doi.org/10.1016/0960-0779(96)00007-0

[19] El Naschie, M.S. (2014) Pinched Material Einstein Space-Time Produces Accelerated Cosmic Expansion. International Journal of Astronomy and Astrophysics, 4, 80-90. https://doi.org/10.4236/ijaa.2014.41009

[20] Nottale, L. (1996) Scale Relativity and Fractal Space-Time: Applications to Quantum Physics, Cosmology and Chaotic Systems. Chaos, Solitons \& Fractals, 7, 877-938. https://doi.org/10.1016/0960-0779(96)00002-1

[21] Marek-Crnjac, L., El Naschie, M.S. and He, J.H. (2013) Chaotic Fractals at the Root of Relativistic Quantum Physics and Cosmology. International Journal of Modern Nonlinear Theory and Application, 2, 78. https://doi.org/10.4236/ijmnta.2013.21A010

[22] El Naschie, M.S. (2005) From Experimental Quantum Optics to Quantum Gravity via a Fuzzy Kähler Manifold. Chaos, Solitons \& Fractals, 25, 969-977. https://doi.org/10.1016/j.chaos.2005.02.028

[23] El Naschie, M.S. (2013) A Resolution of Cosmic Dark Energy via a Quantum Entanglement 
Relativity Theory. Journal of Quantum Information Science, 3, 23. https://doi.org/10.4236/jqis.2013.31006

[24] El Naschie, M.S. (2013) What Is the Missing Dark Energy in a Nutshell and the HawkingHartle Quantum Wave Collapse. International Journal of Astronomy and Astrophysics, 3, 205. https://doi.org/10.4236/ijaa.2013.33024

[25] El Naschie, M.S. (2005) Einstein in a Complex Time-Some Very Personal Thoughts about E-Infinity Theory and Modern Physics. International Journal of Nonlinear Sciences and Numerical Simulation, 6, 331-333. https://doi.org/10.1515/IJNSNS.2005.6.3.331

[26] El Naschie, M.S. (2013) A Rindler-KAM Spacetime Geometry and Scaling the Planck Scale Solves Quantum Relativity and Explains Dark Energy. International Journal of Astronomy and Astrophysics, 3, 483-493. https://doi.org/10.4236/ijaa.2013.34056

[27] He, J.H. (2005) Space, Time and beyond. International Journal of Nonlinear Sciences and Numerical Simulation, 6, 343-346. https://doi.org/10.1515/IJNSNS.2005.6.4.343

[28] El Naschie, M.S. (2013) A Unified Newtonian-Relativistic Quantum Resolution of the Supposedly Missing Dark Energy of the Cosmos and the Constancy of the Speed of Light. International Journal of Modern Nonlinear Theory and Application, 2, 43. https://doi.org/10.4236/ijmnta.2013.21005

[29] El Naschie, M.S. (2013) From Yang-Mills Photon in Curved Spacetime to Dark Energy Density. Journal of Quantum Information Science, 3, 121-126. https://doi.org/10.4236/jqis.2013.34016

[30] He, J.H. (2005) In Search of 9 Hidden Particles. International Journal of Nonlinear Sciences and Numerical Simulation, 6, 93-94. https://doi.org/10.1515/IJNSNS.2005.6.2.93

[31] El Naschie, M.S. (2004) Gravitational Instanton in Hilbert Space and the Mass of High Energy Elementary Particles. Chaos, Solitons \& Fractals, 20, 917-923. https://doi.org/10.1016/j.chaos.2003.11.001

[32] El Naschie, M.S. (2013) Topological-Geometrical and Physical Interpretation of the Dark Energy of the Cosmos as a "Halo" Energy of the Schrödinger Quantum Wave. Journal of Modern Physics, 4, 591. https://doi.org/10.4236/jmp.2013.45084

[33] El Naschie, M. (2014) Cosmic Dark Energy Density from Classical Mechanics and Seemingly Redundant Riemannian Finitely Many Tensor Components of Einstein's General Relativity. World Journal of Mechanics, 4, 153-156. https://doi.org/10.4236/wjm.2014.46017

[34] Sigalotti, L.D.G. and Mejias, A. (2006) On El Naschie's Conjugate Complex. Time, Fractal E $(\infty)$ Space-Time and Faster-Than-Light Particles. International Journal of Nonlinear Sciences and Numerical Simulation, 7, 467-472.

[35] El Naschie, M.S. (1995) On the Nature of Complex Time, Diffusion and the Two-Slit Experiment. Chaos, Solitons \& Fractals, 5, 1031-1032. https://doi.org/10.1016/0960-0779(95)00044-5

[36] El Naschie, M.S. (2006) On Two New Fuzzy Kähler Manifolds, Klein Modular Space and 'tHooft Holographic Principles. Chaos, Solitons \& Fractals, 29, 876-881. https://doi.org/10.1016/j.chaos.2005.12.027

[37] El Naschie, M.S. (2014) The Measure Concentration of Convex Geometry in a Quasi Banach Spacetime behind the Supposedly Missing Dark Energy of the Cosmos. American Journal of Astronomy \& Astrophysics, 2, 72-77. https://doi.org/10.11648/j.ajaa.20140206.13

[38] El Naschie, M.S. (2004) Quantum Gravity from Descriptive Set Theory. Chaos, Solitons \& Fractals, 19, 1339-1344. https://doi.org/10.1016/j.chaos.2003.08.009

[39] El Naschie, M.S. and Helal, A. (2013) Dark Energy Explained via the Hawking-Hartle 
Quantum Wave and the Topology of Cosmic Crystallography. International Journal of Astronomy and Astrophysics, 3, 318. https://doi.org/10.4236/ijaa.2013.33037

[40] Iovane, G. (2005) Self-Similar and Oscillating Solutions of Einstein's Equation and Other Relevant Consequences of a Stochastic Self-Similar and Fractal Universe via El Naschie's $\varepsilon$ $(\infty)$ Cantorian Space-Time. Chaos, Solitons \& Fractals, 23, 351-360.

https://doi.org/10.1016/j.chaos.2004.05.032

[41] El Naschie, M.S. (2014) Compactified Dimensions as Produced by Quantum Entanglement, the Four Dimensionality of Einstein's Smooth Spacetime and 'tHooft's 4- $\varepsilon$ Fractal Spacetime. American Journal of Astronomy \& Astrophysics, 2, 34-37. https://doi.org/10.11648/j.ajaa.20140203.12

[42] El Naschie, M.S. (2007) The Fibonacci Code behind Super Strings and P-Branes. An Answer to M. Kaku's Fundamental Question. Chaos, Solitons \& Fractals, 31, 537-547. https://doi.org/10.1016/j.chaos.2006.07.001

[43] El Naschie, M.S. (2006) Is Einstein's General Field Equation More Fundamental than Quantum Field Theory and Particle Physics? Chaos, Solitons \& Fractals, 30, 525-531. https://doi.org/10.1016/j.chaos.2005.04.123

[44] El Naschie, M.S. (2013) A Fractal Menger Sponge Space-Time Proposal to Reconcile Measurements and Theoretical Predictions of Cosmic Dark Energy. International Journal of Modern Nonlinear Theory and Application, 2, 107. https://doi.org/10.4236/ijmnta.2013.22014

[45] El Naschie, M.S. (2004) How Gravitational Instanton Could Solve the Mass Problem of the Standard Model of High Energy Particle Physics. Chaos, Solitons \& Fractals, 21, 249-260. https://doi.org/10.1016/j.chaos.2003.12.001

[46] El Naschie, M.S. (2004) Quantum Gravity, Clifford Algebras, Fuzzy Set Theory and the Fundamental Constants of Nature. Chaos, Solitons \& Fractals, 20, 437-450. https://doi.org/10.1016/j.chaos.2003.09.029

[47] El Naschie, M.S. (2013) Quantum Entanglement: Where Dark Energy and Negative Gravity plus Accelerated Expansion of the Universe Comes from. Journal of Quantum Information Science, 3, Article ID: 32831. https://doi.org/10.4236/jqis.2013.32011

[48] El Naschie, M.S. (2015) Dark Energy and Its Cosmic Density from Einstein's Relativity and Gauge Fields Renormalization Leading to the Possibility of a New 'tHooft Quasi Particle. The Open Astronomy Journal, 8, 1-17. https://doi.org/10.2174/1874381101508010001

[49] El Naschie, M.S. (2006) The Brain and E-Infinity. International Journal of Nonlinear Sciences and Numerical Simulation, 7, 129-132. https://doi.org/10.1515/ijnsns.2006.7.2.129

[50] El Naschie, M.S. (2014) On a New Elementary Particle from the Disintegration of the Symplectic 'tHooft-Veltman-Wilson Fractal Spacetime. World Journal of Nuclear Science and Technology, 4, Article ID: 50539.

[51] El Naschie, M.S. (2013) Dark Energy from Kaluza-Klein Spacetime and Noether's Theorem via Lagrangian Multiplier Method. Journal of Modern Physics, 4, Article ID: 32975. https://doi.org/10.4236/jmp.2013.46103

[52] Tang, W., Li, Y., Kong, H.Y. and El Naschie, M.S. (2014) From Nonlocal Elasticity to Nonlocal Spacetime and Nano Science. Bubbfil Nanotechnology, 1, 3-12.

[53] Iovane, G. and Benedetto, E. (2005) El Naschie E-Infinity Cantorian Space-Time, Fantappie's Group and Applications in Cosmology. International Journal of Nonlinear Sciences and Numerical Simulation, 6, 357-370. https://doi.org/10.1515/IJNSNS.2005.6.4.357

[54] El Naschie, M.S. (2004) The Symplictic Vacuum, Exotic Quasi Particles and Gravitational Instanton. Chaos, Solitons \& Fractals, 22, 1-11. https://doi.org/10.1016/j.chaos.2004.01.015 
[55] El Naschie, M.S. (2004) The Concepts of E Infinity: An Elementary Introduction to the Cantorian-Fractal Theory of Quantum Physics. Chaos, Solitons \& Fractals, 22, 495-511. https://doi.org/10.1016/j.chaos.2004.02.028

[56] El Naschie, M.S. (2006) Elementary Number Theory in Superstrings, Loop Quantum Mechanics, Twistors and E-Infinity High Energy Physics. Chaos, Solitons \& Fractals, 27, $297-$ 330. https://doi.org/10.1016/j.chaos.2005.04.116

[57] Iovane, G. (2005) Mohamed El Naschie's $\epsilon(\infty)$ Cantorian Space-Time and Its Consequences in Cosmology. Chaos, Solitons \& Fractals, 25, 775-779. https://doi.org/10.1016/j.chaos.2005.02.024

[58] El Naschie, M.S. and Marek-Crnjac, L. (2012) Deriving the Exact Percentage of Dark Energy Using a Transfinite Version of Nottale's Scale Relativity. International Journal of Modern Nonlinear Theory and Application, 1, 118. https://doi.org/10.4236/ijmnta.2012.14018

[59] El Naschie, M.S. (2000) On the Unification of the Fundamental Forces and Complex Time in the E $(\infty)$ Space. Chaos, Solitons \& Fractals, 11, 1149-1162. https://doi.org/10.1016/S0960-0779(99)00185-X

[60] El Naschie, M.S. (2006) Intermediate Prerequisites for E-Infinity Theory (Further Recommended Reading in Nonlinear Dynamics and Mathematical Physics). Chaos, Solitons \& Fractals, 30, 622-628. https://doi.org/10.1016/j.chaos.2006.04.042

[61] El Naschie, M.S. (2014) Dark Energy via Quantum Field Theory in Curved Spacetime. Journal of Modern Physics and Applications, 2, 1-7.

[62] El Naschie, M.S. (2013) Nash Embedding of Witten's M-Theory and the Hawking-Hartle Quantum Wave of Dark Energy. Journal of Modern Physics, 4, 1417.

https://doi.org/10.4236/jmp.2013.410170

[63] El Naschie, M.S. (2013) The Hyperbolic Extension of Sigalotti-Hendi-Sharifzadeh's Golden Triangle of Special Theory of Relativity and the Nature of Dark Energy. Journal of Modern Physics, 4, 354. https://doi.org/10.4236/jmp.2013.43049

[64] El Naschie, M.S. (2003) Modular Groups in Cantorian E( $\infty$ ) High-Energy Physics. Chaos, Solitons \& Fractals, 16, 353-366. https://doi.org/10.1016/S0960-0779(02)00440-X

[65] El Naschie, M.S. (2014) From $\mathrm{E}=\mathrm{mc}^{2}$ to $\mathrm{E}=\mathrm{mc}^{2} / 22-\mathrm{A}$ Short Account of the Most Famous Equation in Physics and Its Hidden Quantum Entanglement Origin. Journal of Quantum Information Science, 4, 284. https://doi.org/10.4236/jqis.2014.44023

[66] El Naschie, M.S. (1993) Statistical Mechanics of Multi-Dimensional Cantor Sets, Gödel Theorem and Quantum Spacetime. Journal of the Franklin Institute, 330, 199-211. https://doi.org/10.1016/0016-0032(93)90030-X

[67] El Naschie, M.S. (2003) The VAK of Vacuum Fluctuation: Spontaneous Self-Organization and Complexity Theory Interpretation of High Energy Particle Physics and the Mass Spectrum. Chaos, Solitons \& Fractals, 18, 401-420. https://doi.org/10.1016/S0960-0779(03)00098-5

[68] El-Ahmady, A.E. (2007) The Variation of the Density Functions on Chaotic Spheres in Chaotic Space-Like Minkowskispace Time. Chaos, Solitons \& Fractals, 31, 1272-1278. https://doi.org/10.1016/j.chaos.2005.10.112

[69] El Naschie, M.S. (2005) On 336 Kissing Spheres in 10 Dimensions, 528 P-Brane States in 11 Dimensions and the 60 Elementary Particles of the Standard Model. Chaos, Solitons \& Fractals, 24, 447-457. https://doi.org/10.1016/j.chaos.2004.09.071

[70] El Naschie, M.S. (2014) Entanglement of E8E8 Exceptional Lie Symmetry Group Dark Energy, Einstein's Maximal Total Energy and the Hartle-Hawking No Boundary Proposal as the Explanation for Dark Energy. World Journal of Condensed Matter Physics, 4, 74-77. 
https://doi.org/10.4236/wjcmp.2014.42011

[71] El Naschie, M.S. (2014) To Dark Energy Theory from a Cosserat-Like Model of Spacetime. Problems of Nonlinear Analysis in Engineering Systems, 20, 79-98.

[72] El Naschie, M.S. (2014) Cosmic Dark Energy from 't Hooft's Dimensional Regularization and Witten's Topological Quantum Field Pure Gravity. Journal of Quantum Information Science, 4, 83-91. https://doi.org/10.4236/jqis.2014.42008

[73] Helal, M.A., Marek-Crnjac, L. and He, J.H. (2013) The Three Page Guide to the Most Important Results of MS El Naschie's Research in E-Infinity Quantum Physics and Cosmology. Open Journal of Microphysics, 3, 141. https://doi.org/10.4236/ojm.2013.34020

[74] El Naschie, M.S. (2007) Feigenbaum Scenario for Turbulence and Cantorian E-Infinity Theory of High Energy Particle Physics. Chaos, Solitons \& Fractals, 32, 911-915. https://doi.org/10.1016/j.chaos.2006.08.014

[75] El Naschie, M.S. (2008) Symmetry Group Prerequisite for E-Infinity in High Energy Physics. Chaos, Solitons \& Fractals, 35, 202-211. https://doi.org/10.1016/j.chaos.2007.05.006

[76] El Naschie, M.S. (2014) Capillary Surface Energy Elucidation of the Cosmic Dark EnergyOrdinary Energy Duality. Open Journal of Fluid Dynamics, 4, 15-17. https://doi.org/10.4236/ojfd.2014.41002

[77] El Naschie, M.S. (2016) Cosserat-Cartan and de Sitter-Witten Spacetime Setting for Dark Energy. Quantum Matter, 5, 1-4. https://doi.org/10.1166/qm.2016.1247

[78] El Naschie, M.S. (2015) An Exact Mathematical Picture of Quantum Spacetime. Advances in Pure Mathematics, 5, 560. https://doi.org/10.4236/apm.2015.59052

[79] El Naschie, M.S. (2007) Exceptional Lie Groups Hierarchy and the Structure of the Micro Universe. International Journal of Nonlinear Sciences and Numerical Simulation, 8, 445450. https://doi.org/10.1515/IJNSNS.2007.8.3.445

[80] Marek-Crnjac, L. and He, J. (2013) An Invitation to El Naschie's Theory of Cantorian Space-Time and Dark Energy. International Journal of Astronomy and Astrophysics, 3, 464-471. https://doi.org/10.4236/ijaa.2013.34053

[81] El Naschie, M.S. (1997) COBE Satellite Measurement, Cantorian Space and Cosmic Strings. Chaos, Solitons \& Fractals, 8, 847-850. https://doi.org/10.1016/S0960-0779(97)00084-2

[82] El Naschie, M.S. (2006) Linderhof Room of Mirrors, Thurston Three-Manifolds and the Geometry of Our Universe. International Journal of Nonlinear Sciences and Numerical Simulation, 7, 97-100. https://doi.org/10.1515/ijnsns.2006.7.1.97

[83] El Naschie, M.S. (2015) A Resolution of the Black Hole Information Paradox via Transfinite Set Theory. World Journal of Condensed Matter Physics, 5, 249. https://doi.org/10.4236/wjcmp.2015.54026

[84] El Naschie, M.S. (2014) Why E Is Not Equal to mc². Journal of Modern Physics, 5, 743-750. https://doi.org/10.4236/jmp.2014.59084

[85] El Naschie, M.S. (2005) On a Class of Fuzzy Kähler-Like Manifolds. Chaos, Solitons \& Fractals, 26, 257-261. https://doi.org/10.1016/j.chaos.2004.12.024

[86] El Naschie, M.S. (2005) Gödel Universe, Dualities and High Energy Particles in E-Infinity. Chaos, Solitons \& Fractals, 25, 759-764. https://doi.org/10.1016/j.chaos.2004.12.010

[87] El Naschie, M.S. (1998) On the Irreducibility of Spatial Ambiguity in Quantum Physics. Chaos, Solitons \& Fractals, 9, 913-919. https://doi.org/10.1016/S0960-0779(97)00165-3

[88] El Naschie, M.S. (2013) The Quantum Entanglement behind the Missing Dark Energy. Journal of Modern Physics and Applications, 2, 88-96.

[89] El Naschie, M.S. (2005) Deriving the Essential Features of the Standard Model from the 
General Theory of Relativity. Chaos, Solitons \& Fractals, 24, 941-946.

https://doi.org/10.1016/j.chaos.2004.10.001

[90] El Naschie, M.S. (2014) Einstein's General Relativity and Pure Gravity in a Cosserat and De Sitter-Witten Spacetime Setting as the Explanation of Dark Energy and Cosmic Accelerated Expansion. International Journal of Astronomy and Astrophysics, 4, 332. https://doi.org/10.4236/ijaa.2014.42027

[91] El Naschie, M.S. (2006) The Unreasonable Effectiveness of the Electron-Volt Units System in High Energy Physics and the Role Played by $\bar{\alpha}_{0}=137$. International Journal of Nonlinear Sciences and Numerical Simulation, 7, 119-128. https://doi.org/10.1515/IJNSNS.2006.7.2.119

[92] El Naschie, M.S. (1998) Superstrings, Knots, and Noncommutative Geometry in $\mathrm{E}^{(\infty)}$ Space. International Journal of Theoretical Physics, 37, 2935-2951. https://doi.org/10.1023/A:1026679628582

[93] El Naschie, M.S. (2013) The Missing Dark Energy of the Cosmos from Light Cone Topological Velocity and Scaling of the Planck Scale. Open Journal of Microphysics, 3, 64-70. https://doi.org/10.4236/ojm.2013.33012

[94] El Naschie, M.S. (2008) The Fundamental Algebraic Equations of the Constants of Nature. Chaos, Solitons \& Fractals, 35, 320-322. https://doi.org/10.1016/j.chaos.2007.06.110

[95] Iovane, G. (2006) El Naschie E-Infinity Cantorian Spacetime and Lengths Scales in Cosmology. International Journal of Nonlinear Sciences and Numerical Simulation, 7, 155-162. https://doi.org/10.1515/IJNSNS.2006.7.2.155

[96] El Naschie, M.S. (2014) The Meta Energy of Dark Energy. Open Journal of Philosophy, 4, 157-159. https://doi.org/10.4236/ojpp.2014.42022

[97] El Naschie, M.S. (2007) From Symmetry to Particles. Chaos, Solitons \& Fractals, 32, $427-$ 430. https://doi.org/10.1016/j.chaos.2006.09.016

[98] El Naschie, M.S. (2008) Kaluza-Klein Unification-Some Possible Extensions. Chaos, Solitons \& Fractals, 37, 16-22. https://doi.org/10.1016/j.chaos.2007.09.079

[99] El Naschie, M.S. (2015) On a Non-Perturbative Quantum Relativity Theory Leading to a Casimir-Dark Energy Nanotech Reactor Proposal. Open Journal of Applied Sciences, 5, 313. https://doi.org/10.4236/ojapps.2015.57032

[100] He, J.H. (2007) Nonlinear Dynamics and the Nobel Prize in Physics. International Journal of Nonlinear Sciences and Numerical Simulation, 8, 1-4. https://doi.org/10.1515/IJNSNS.2007.8.1.1

[101] El Naschie, M.S. (2004) Small World Network, $\varepsilon(\infty)$ Topology and the Mass Spectrum of High Energy Particles Physics. Chaos, Solitons \& Fractals, 19, 689-697. https://doi.org/10.1016/S0960-0779(03)00337-0

[102] El Naschie, M.S. (2014) From Chern-Simon, Holography and Scale Relativity to Dark Energy. Journal of Applied Mathematics and Physics, 2, 634-638. https://doi.org/10.4236/jamp.2014.27069

[103] El Naschie, M.S. (2005) Experimental and Theoretical Arguments for the Number and the Mass of the Higgs Particles. Chaos, Solitons \& Fractals, 23, 1091-1098. https://doi.org/10.1016/j.chaos.2004.08.001

[104] He, J.H. (2006) Application of E-Infinity Theory to Biology. Chaos, Solitons \& Fractals, 28, 285-289. https://doi.org/10.1016/j.chaos.2005.08.001

[105] He, J.H. and Marek-Crnjac, L. (2013) Mohamed El Naschie's Revision of Albert Einstein's E $=\mathrm{m}_{0} \mathrm{c}^{2}$ : A Definite Resolution of the Mystery of the Missing Dark Energy of the Cosmos. International Journal of Modern Nonlinear Theory and Application, 2, 55-59. 
https://doi.org/10.4236/ijmnta.2013.21006

[106] El Naschie, M.S. (1998) Dimensional Symmetry Breaking, Information and Fractal Gravity in Cantorian Space. Biosystems, 46, 41-46. https://doi.org/10.1016/S0303-2647(97)00079-8

[107] El Naschie, M.S. (2005) On Einstein's Super Symmetric Tensor and the Number of Elementary Particles of the Standard Model. Chaos, Solitons \& Fractals, 23, 1521-1525. https://doi.org/10.1016/j.chaos.2004.09.003

[108] El Naschie, M.S. (2001) A General Theory for the Topology of Transfinite Heterotic Strings and Quantum Gravity. Chaos, Solitons \& Fractals, 12, 969-988. https://doi.org/10.1016/S0960-0779(00)00263-0

[109] El Naschie, M.S. (2006) Fuzzy Dodecahedron Topology and E-Infinity Spacetime as a Model for Quantum Physics. Chaos, Solitons \& Fractals, 30, 1025-1033. https://doi.org/10.1016/j.chaos.2006.05.088

[110] El Naschie, M.S. (2013) Determining the Missing Dark Energy Density of the Cosmos from a Light Cone Exact Relativistic Analysis. Journal of Physics, 2, 18-23.

[111] El Naschie, M.S., Marek-Crnjac, L., Helal, M.A. and He, J.H. (2014) A Topological Magueijo-Smolin Varying Speed of Light Theory, the Accelerated Cosmic Expansion and the Dark Energy of Pure Gravity. Applied Mathematics, 5, 1780-1790. https://doi.org/10.4236/am.2014.512171

[112] Sigalotti, L.D.G. and Mejias, A. (2006) The Golden Ratio in Special Relativity. Chaos, Solitons \& Fractals, 30, 521-524. https://doi.org/10.1016/j.chaos.2006.03.005

[113] Castro, C., El-Naschie, M.S. and Granik, A. (2000) Why We Live in $3+1$ Dimensions. CERN Document Server. (No. hep-th/0004152).

[114] Marek Crnjac, L. and El Naschie, M.S. (2013) Quantum Gravity and Dark Energy Using Fractal Planck Scaling. Journal of Modern Physics, 4, 31-38. https://doi.org/10.4236/jmp.2013.411A1005

[115] El Naschie, M.S. (2016) Einstein-Rosen Bridge (ER), Einstein-Podolsky-Rosen Experiment (EPR) and Zero Measure Rindler-KAM Cantorian Spacetime Geometry (ZMG) Are Conceptually Equivalent. Journal of Quantum Information Science, 6, 1-9. https://doi.org/10.4236/jqis.2016.61001

[116] El Naschie, M.S. (1993) On Certain Infinite Dimensional Cantor Sets and the Schrödinger Wave. Chaos, Solitons \& Fractals, 3, 89-98. https://doi.org/10.1016/0960-0779(93)90042-Y

[117] El Naschie, M.S. (1995) Statistical Geometry of a Cantor Discretum and Semiconductors. Computers \& Mathematics with Applications, 29, 103-110. https://doi.org/10.1016/0898-1221(95)00062-4

[118] El Naschie, M.S. (2003) Kleinian Groups in E( $\infty)$ and Their Connection to Particle Physics and Cosmology. Chaos, Solitons \& Fractals, 16, 637-649. https://doi.org/10.1016/S0960-0779(02)00489-7

[119] El Naschie, M.S. (2014) Electromagnetic-Pure Gravity Connection via Hardy's Quantum Entanglement. Journal of Electromagnetic Analysis and Applications, 6, 233. https://doi.org/10.4236/jemaa.2014.69023

[120] El Naschie, M.S. (2013) Experimentally Based Theoretical Arguments That Unruh's Temperature, Hawking's Vacuum Fluctuation and Rindler's Wedge Are Physically Real. American Journal of Modern Physics, 2, 357-361. https://doi.org/10.11648/j.ajmp.20130206.23

[121] El Naschie, M.S. (2015) Kerr Black Hole Geometry Leading to Dark Matter and Dark Energy via E-Infinity Theory and the Possibility of a Nano Spacetime Singularities Reactor. Natural Science, 7, 210. https://doi.org/10.4236/ns.2015.74024 
[122] Castro, C. (2000) Is Quantum Space-Time Infinite Dimensional. Chaos, Solitons \& Fractals, 11, 1663-1670. https://doi.org/10.1016/S0960-0779(00)00018-7

[123] El Naschie, M.S. (2014) Calculating the Exact Experimental Density of the Dark Energy in the Cosmos Assuming a Fractal Speed of Light. International Journal of Modern Nonlinear Theory and Application, 3, 1-5. https://doi.org/10.4236/ijmnta.2014.31001

[124] El Naschie, M.S. (2004) Topological Defects in the Symplictic Vacuum, Anomalous Positron Production and the Gravitational Instanton. International Journal of Modern Physics E, 13, 835-849. https://doi.org/10.1142/S0218301304002429

[125] El Naschie, M.S. (2000) Towards a Geometrical Theory for the Unification of All Fundamental Forces. Chaos, Solitons \& Fractals, 11, 1459-1469. https://doi.org/10.1016/S0960-0779(99)00194-0

[126] El Naschie, M.S. (2014) From Modified Newtonian Gravity to Dark Energy via Quantum Entanglement. Journal of Applied Mathematics and Physics, 2, 803. https://doi.org/10.4236/jamp.2014.28088

[127] El Naschie, M.S. (2001) On a Heterotic String-Based Algorithm for the Determination of the Fine Structure Constant. Chaos, Solitons \& Fractals, 12, 539-549. https://doi.org/10.1016/S0960-0779(00)00187-9

[128] El Naschie, M.S. (2005) Determining the Number of Higgs Particles Starting from General Relativity and Various Other Field Theories. Chaos, Solitons \& Fractals, 23, 711-726. https://doi.org/10.1016/j.chaos.2004.06.048

[129] El Naschie, M.S. (2015) Quantum Fractals and the Casimir-Dark Energy Duality-The Road to a Clean Quantum Energy Nano Reactor. Journal of Modern Physics, 6, 1321. https://doi.org/10.4236/jmp.2015.69137

[130] Iovane, G. and Giordano, P. (2007) Wavelets and Multiresolution Analysis: Nature of $\varepsilon(\infty)$ Cantorian Space-Time. Chaos, Solitons \& Fractals, 32, 896-910. https://doi.org/10.1016/j.chaos.2005.11.097

[131] He, J.H., Liu, Y., Xu, L. and Yu, J.Y. (2007) Micro Sphere with Nanoporosity by Electrospinning. Chaos, Solitons \& Fractals, 32, 1096-1100. https://doi.org/10.1016/j.chaos.2006.07.045

[132] Chen, W. (2006) Time-Space Fabric Underlying Anomalous Diffusion. Chaos, Solitons \& Fractals, 28, 923-929. https://doi.org/10.1016/j.chaos.2005.08.199

[133] El Naschie, M.S. (2006) Is Gravity Less Fundamental than Elementary Particles Theory? Critical Remarks on Holography and E-Infinity Theory. Chaos, Solitons \& Fractals, 29, 803-807. https://doi.org/10.1016/j.chaos.2006.01.012

[134] El Naschie, M.S. (2008) Average Exceptional Lie and Coxeter Group Hierarchies with Special Reference to the Standard Model of High Energy Particle Physics. Chaos, Solitons \& Fractals, 37, 662-668. https://doi.org/10.1016/j.chaos.2008.01.018

[135] El Naschie, M.S. (2015) Hubble Scale Dark Energy Meets Nano Scale Casimir Energy and the Rational of Their T-Duality and Mirror Symmetry Equivalence. World Journal of Nano Science and Engineering, 5, 57. https://doi.org/10.4236/wjnse.2015.53008

[136] El Naschie, M.S. (2005) Determining the Mass of the Higgs and the Electroweak Bosons. Chaos, Solitons \& Fractals, 24, 899-905. https://doi.org/10.1016/j.chaos.2004.11.003

[137] El Naschie, M.S. (2015) From Kantian-Reinen Fernunft to the Real Dark Energy Density of the Cosmos via the Measure Concentration of Convex Geometry in Quasi Banach Spacetime. Open Journal of Philosophy, 5, 123. https://doi.org/10.4236/ojpp.2015.51014

[138] El Naschie, M.S. (2014) Rindler Space Derivation of Dark Energy. Journal of Modern Physics and Applications, 6, 1-10. 
[139] Marek-Crnjac, L. and El Naschie, M.S. (2013) Chaotic Fractal Tiling for the Missing Dark Energy and Veneziano Model. Applied Mathematics, 4, 22. https://doi.org/10.4236/am.2013.411A2005

[140] Nottale, L. (1999) The Scale-Relativity Program. Chaos, Solitons \& Fractals, 10, 459-468. https://doi.org/10.1016/S0960-0779(98)00195-7

[141] El Naschie, M.S. (2013) The Hydrogen Atom Fractal Spectra, the Missing Dark Energy of the Cosmos and Their Hardy Quantum Entanglement. International Journal of Modern Nonlinear Theory and Application, 2, 167. https://doi.org/10.4236/ijmnta.2013.23023

[142] El Naschie, M.S. (2005) A New Solution for the Two-Slit Experiment. Chaos, Solitons \& Fractals, 25, 935-939. https://doi.org/10.1016/j.chaos.2005.02.029

[143] He, J.H. (2007) On the Number of Elementary Particles in a Resolution Dependent Fractal Spacetime. Chaos, Solitons \& Fractals, 32, 1645-1648. https://doi.org/10.1016/j.chaos.2006.08.015

[144] Gottlieb, I., Agop, M., Ciobanu, G. and Stroe, A. (2006) El Naschie's $\varepsilon(\infty)$ Space-Time and New Results in Scale Relativity Theories. Chaos, Solitons \& Fractals, 30, 380-398. https://doi.org/10.1016/j.chaos.2005.11.018

[145] El Naschie, M.S. (2015) The Cantorian Monadic Plasma behind the Zero Point Vacuum Spacetime Energy. American Journal of Nano Research and Application, 3, 66-70.

[146] Gottlieb, I., Agop, M. and Jarcau, M. (2004) El Naschie's Cantorian Space-Time and General Relativity by Means of Barbilian's Group: A Cantorian Fractal Axiomatic Model of Space-Time. Chaos, Solitons \& Fractals, 19, 705-730. https://doi.org/10.1016/S0960-0779(03)00244-3

[147] El Naschie, M.S. (2009) On Zero-Dimensional Points Curvature in the Dynamics of Cantorian-Fractal Spacetime Setting and High Energy Particle Physics. Chaos, Solitons \& Fractals, 41, 2725-2732. https://doi.org/10.1016/j.chaos.2008.10.001

[148] El Naschie, M.S. (2008) High Energy Physics and the Standard Model from the Exceptional Lie Groups. Chaos, Solitons \& Fractals, 36, 1-17. https://doi.org/10.1016/j.chaos.2007.08.058

[149] El Naschie, M.S. (2001) On Twistors in Cantorian E ( $\infty)$ Space. Chaos, Solitons \& Fractals, 12, 741-746. https://doi.org/10.1016/S0960-0779(00)00193-4

[150] El Naschie, M.S. (2005) Non-Euclidean Spacetime Structure and the Two-Slit Experiment. Chaos, Solitons \& Fractals, 26, 1-6. https://doi.org/10.1016/j.chaos.2005.02.031

[151] El Naschie, M.S. and Rossler, O.E. (1994) Quantum Mechanics and Chaotic Fractals. Chaos, Solitons \& Fractals, 4, 307-309. https://doi.org/10.1016/0960-0779(94)90049-3

[152] Nottale, L. (1995) Scale Relativity: From Quantum Mechanics to Chaotic Dynamics. Chaos, Solitons \& Fractals, 6, 399-410. https://doi.org/10.1016/0960-0779(95)80047-K

[153] Marek-Crnjac, L. (2009) A Short History of Fractal-Cantorian Space-Time. Chaos, Solitons \& Fractals, 41, 2697-2705. https://doi.org/10.1016/j.chaos.2008.10.007

[154] Marek-Crnjac, L. (2015) On El Naschie's Fractal-Cantorian Space-Time and Dark EnergyA Tutorial Review. Natural Science, 7, 581. https://doi.org/10.4236/ns.2015.713058

[155] He, J.H. (2014) A Tutorial Review on Fractal Spacetime and Fractional Calculus. International Journal of Theoretical Physics, 53, 3698-3718. https://doi.org/10.1007/s10773-014-2123-8

[156] El Naschie, M.S. (2005) Kähler-Like Manifolds, Weyl Spinor Particles and E-Infinity High Energy Physics. Chaos, Solitons \& Fractals, 26, 665-670.

https://doi.org/10.1016/j.chaos.2005.01.018 
[157] El Naschie, M.S. (2005) A P-Brane Vindication of the Two Higgs-Doublet Minimally Super-Symmetric Standard Model and Related Issues. Chaos, Solitons \& Fractals, 23, 15111514. https://doi.org/10.1016/j.chaos.2004.08.008

[158] Agop, M., Griga, V., Ciobanu, B., Ciubotariu, C., Buzea, C.G., Stan, C. and Buzea, C. (1998) Gravity and Cantorian Space-Time. Chaos, Solitons \& Fractals, 9, 1143-1181. https://doi.org/10.1016/S0960-0779(98)80005-2

[159] Giordano, P., Iovane, G. and Laserra, E. (2007) El Naschie $\epsilon(\infty)$ Cantorian Structures with Spatial Pseudo-Spherical Symmetry: A Possible Description of the Actual Segregated Universe. Chaos, Solitons \& Fractals, 31, 1108-1117.

https://doi.org/10.1016/j.chaos.2006.03.114

[160] El Naschie, M.S. (2005) The Supersymmetric Components of the Riemann-Einstein Tensor as Nine Dimensional Spheres in Ten Dimensional Space. Chaos, Solitons \& Fractals, 24, 29 32. https://doi.org/10.1016/j.chaos.2004.09.002

[161] He, J.H. (2007) E-Infinity Theory and the Higgs Field. Chaos, Solitons \& Fractals, 31, 782786. https://doi.org/10.1016/j.chaos.2006.04.041

[162] Iovane, G., Giordano, P. and Salerno, S. (2005) Dynamical Systems on El Naschie's $\varepsilon(\infty)$ Cantorian Space-Time. Chaos, Solitons \& Fractals, 24, 423-441. https://doi.org/10.1016/j.chaos.2004.09.068

[163] El Naschie, M.S. (2003) On John Nash's Crumpled Surface. Chaos, Solitons \& Fractals, 18, 635-641. https://doi.org/10.1016/S0960-0779(03)00007-9

[164] El Naschie, M.S. (2016) On a Fractal Version of Witten's M-Theory. International Journal of Astronomy and Astrophysics, 6, 135. https://doi.org/10.4236/ijaa.2016.62011

[165] El Naschie, M.S. (2008) The Exceptional Lie Symmetry Groups Hierarchy and the Expected Number of Higgs Bosons. Chaos, Solitons \& Fractals, 35, 268-273. https://doi.org/10.1016/j.chaos.2007.07.036

[166] El Naschie, M.S. (2015) The Casimir Topological Effect and a Proposal for a Casimir-Dark Energy Nano Reactor. World Journal of Nano Science and Engineering, 5, 26. https://doi.org/10.4236/wjnse.2015.51004

[167] El Naschie, M.S. (2008) Exact Non-Perturbative Derivation of Gravity's Fine Structure Constant, the Mass of the Higgs and Elementary Black Holes. Chaos, Solitons \& Fractals, 37, 346-359. https://doi.org/10.1016/j.chaos.2007.10.021

[168] El Naschie, M.S. (2015) From Fusion Algebra to Cold Fusion or from Pure Reason to Pragmatism. Open Journal of Philosophy, 5, 319. https://doi.org/10.4236/ojpp.2015.56040

[169] El Naschie, M.S. (2015) If Quantum “Wave” of the Universe Then Quantum "Particle" of the Universe: A Resolution of the Dark Energy Question and the Black Hole Information Paradox. International Journal of Astronomy and Astrophysics, 5, 243. https://doi.org/10.4236/ijaa.2015.54027

[170] Rössler, O.E. (1996) Relative-State Theory: Four New Aspects. Chaos, Solitons \& Fractals, 7, 845-852. https://doi.org/10.1016/0960-0779(95)00117-4

[171] Nottale, L. (1998) Scale Relativity and Schrödinger's Equation. Chaos, Solitons \& Fractals, 9, 1051-1061. https://doi.org/10.1016/S0960-0779(97)00190-2

[172] El Naschie, M.S. (2005) On Penrose View of Transfinite Sets and Computability and the Fractal Character of E-Infinity Spacetime. Chaos, Solitons \& Fractals, 25, 531-533. https://doi.org/10.1016/j.chaos.2005.01.001

[173] Iovane, G. (2006) Cantorian Space-Time and Hilbert Space: Part II-Relevant Consequences. Chaos, Solitons \& Fractals, 29, 1-22. https://doi.org/10.1016/j.chaos.2005.10.045

[174] Czajko, J. (2000) On Conjugate Complex Time-I: Complex Time Implies Existence of 
Tangential Potential That Can Cause Some Equipotential Effects of Gravity. Chaos, Solitons \& Fractals, 11, 1983-1992. https://doi.org/10.1016/S0960-0779(99)00091-0

[175] El Naschie, M.S. (2005) Dead or Alive: Desperately Seeking Schrödinger's Cat. Chaos, Solitons \& Fractals, 26, 673-676. https://doi.org/10.1016/j.chaos.2005.02.030

[176] Nottale, L. (1994) Scale Relativity, Fractal Space-Time and Quantum Mechanics. Chaos, Solitons \& Fractals, 4, 361-388. https://doi.org/10.1016/0960-0779(94)90051-5

[177] El Naschie, M.S. (2015) Application of Dvoretzky's Theorem of Measure Concentration in Physics and Cosmology. Open Journal of Microphysics, 5, 11. https://doi.org/10.4236/ojm.2015.52002

[178] El Naschie, M.S. (2004) Quantum Collapse of Wave Interference Pattern in the Two-Slit Experiment: A Set Theoretical Resolution. Nonlinear Science Letter A, 2, 1-9.

[179] Iovane, G. (2006) Cantorian Spacetime and Hilbert Space: Part I-Foundations. Chaos, Solitons \& Fractals, 28, 857-878. https://doi.org/10.1016/j.chaos.2005.08.074

[180] El Naschie, M.S. (1992) On the Uncertainty of Information in Quantum Space-Time. Chaos, Solitons \& Fractals, 2, 91-94. https://doi.org/10.1016/0960-0779(92)90050-W

[181] Iovane, G., Gargiulo, G. and Zappale, E. (2006) A Cantorian Potential Theory for Describing Dynamical Systems on El Naschie's Space-Time. Chaos, Solitons \& Fractals, 27, 588598. https://doi.org/10.1016/j.chaos.2005.05.015

[182] El Naschie, M.S. (1998) COBE Satellite Measurement, Hyperspheres, Superstrings and the Dimension of Spacetime. Chaos, Solitons \& Fractals, 9, 1445-1471. https://doi.org/10.1016/S0960-0779(98)00120-9

[183] El Naschie, M.S. (2006) On the Vital Role Played by the Electron-Volt Units System in High Energy Physics and Mach's Principle of "Denkökonomie". Chaos, Solitons \& Fractals, 28, 1366-1371. https://doi.org/10.1016/j.chaos.2005.11.001

[184] El Naschie, M.S. (2015) Computing Dark Energy and Ordinary Energy of the Cosmos as a Double Eigenvalue Problem. Journal of Modern Physics, 6, 384. https://doi.org/10.4236/jmp.2015.64042

[185] Elnaschie, M.S. (2005) The Feynman Path Integral and E-Infinity from the Two-Slit Gedanken Experiment. International Journal of Nonlinear Sciences and Numerical Simulation, 6, 335-342. https://doi.org/10.1515/IJNSNS.2005.6.4.335

[186] Iovane, G., Chinnici, M. and Tortoriello, F.S. (2008) Multifractals and El Naschie E-Infinity Cantorian Space-Time. Chaos, Solitons \& Fractals, 35, 645-658. https://doi.org/10.1016/j.chaos.2007.07.051

[187] El Naschie, M.S. (2015) A Cold Fusion-Casimir Energy Nano Reactor Proposal. World Journal of Nano Science and Engineering, 5, 49. https://doi.org/10.4236/wjnse.2015.52007

[188] El Naschie, M.S. (2014) From Highly Structured E-Infinity Rings and Transfinite Maximally Symmetric Manifolds to the Dark Energy Density of the Cosmos. Advances in Pure Mathematics, 4, 641. https://doi.org/10.4236/apm.2014.412073

[189] Selvam, A.M. and Fadnavis, S. (1999) Superstrings, Cantorian-Fractal Spacetime and Quantum-Like Chaos in Atmospheric Flows. Chaos, Solitons \& Fractals, 10, 1321-1334. https://doi.org/10.1016/S0960-0779(98)00150-7

[190] El Naschie, M.S. (2006) Advanced Prerequisite for E-Infinity Theory. Chaos, Solitons \& Fractals, 30, 636-641. https://doi.org/10.1016/j.chaos.2006.04.044

[191] He, J.H. (2006) Application of E-Infinity Theory to Turbulence. Chaos, Solitons \& Fractals, 30, 506-511. https://doi.org/10.1016/j.chaos.2005.11.033

[192] Marek-Crnjac, L. (2013) Modification of Einstein's $\mathrm{E}=\mathrm{mc}^{2}$ to $\mathrm{E}=(1 / 22) \mathrm{mc}^{2}$. American 
Journal of Modern Physics, 2, 255-263. https://doi.org/10.11648/j.ajmp.20130205.14

[193] El-Ahmady, A.E. and Rafat, H. (2006) A Calculation of Geodesics in Chaotic Flat Space and Its Folding. Chaos, Solitons \& Fractals, 30, 836-844. https://doi.org/10.1016/j.chaos.2005.05.033

[194] El Naschie, M.S. (2016) Quantum Dark Energy from the Hyperbolic Transfinite Cantorian Geometry of the Cosmos. Natural Science, 8, 152. https://doi.org/10.4236/ns.2016.83018

[195] Selvam, A.M. and Fadnavis, S. (1999) Cantorian Fractal Spacetime, Quantum-Like Chaos and Scale Relativity in Atmospheric Flows. Chaos, Solitons \& Fractals, 10, 1577-1582. https://doi.org/10.1016/S0960-0779(98)00209-4

[196] He, J.H. and Marek-Crnjac, L. (2013) The Quintessence of El Naschie's Theory of Fractal Relativity and Dark Energy. Fractal Spacetime and Noncommutative Geometry in Quantum and High Energy Physics, 3, 130-137.

[197] El Naschie, M.S. (2008) Noether's Theorem, Exceptional Lie Groups Hierarchy and Determining $1 / \alpha \cong 137$ of Electromagnetism. Chaos, Solitons \& Fractals, 35, 99-103. https://doi.org/10.1016/j.chaos.2007.05.005

[198] El Naschie, M.S. (2007) Quantum Probability without a Phase and a Topological Resolution of the Two-Slit Experiment. International Journal of Nonlinear Sciences and Numerical Simulation, 8, 195-198. https://doi.org/10.1515/IJNSNS.2007.8.2.195

[199] El Naschie, M.S. (2009) Higgs Mechanism, Quarks Confinement and Black Holes as a Cantorian Spacetime Phase Transition Scenario. Chaos, Solitons \& Fractals, 41, 869-874. https://doi.org/10.1016/j.chaos.2008.04.013

[200] El Naschie, M.S. (1994) Quantum Measurement, Diffusion and Cantorian Geodesics. Chaos, Solitons \& Fractals, 4, 1235-1247. https://doi.org/10.1016/0960-0779(94)90034-5

[201] Özgür, C. (2008) N (k)-Quasi Einstein Manifolds Satisfying Certain Conditions. Chaos, Solitons \& Fractals, 38, 1373-1377. https://doi.org/10.1016/j.chaos.2008.03.016

[202] He, J.H. (2007) Shrinkage of Body Size of Small Insects: A Possible Link to Global Warming? Chaos, Solitons \& Fractals, 34, 727-729. https://doi.org/10.1016/j.chaos.2006.04.052

[203] Castro, C. (2001) Noncommutative Geometry, Negative Probabilities and Cantorian-Fractal Spacetime. Chaos, Solitons \& Fractals, 12, 101-104. https://doi.org/10.1016/S0960-0779(00)00196-X

[204] Rami, E.N.A. (2009) On the Fractional Minimal Length Heisenberg-Weyl Uncertainty Relation from Fractional Riccati Generalized Momentum Operator. Chaos, Solitons \& Fractals, 42, 84-88. https://doi.org/10.1016/j.chaos.2008.10.031

[205] Babchin, A.J. and El Naschie, M.S. (2015) On the Real Einstein Beauty E $=\mathrm{kmc}^{2}$. World Journal of Condensed Matter Physics, 6, 1. https://doi.org/10.4236/wjcmp.2016.61001

[206] He, J.H. (2008) String Theory in a Scale Dependent Discontinuous Space-Time. Chaos, Solitons \& Fractals, 36, 542-545. https://doi.org/10.1016/j.chaos.2007.07.093

[207] Nagasawa, M. (1996) Quantum Theory, Theory of Brownian Motions, and Relativity Theory. Chaos, Solitons \& Fractals, 7, 631-643. https://doi.org/10.1016/0960-0779(95)00115-8

[208] Iovane, G., Giordano, P. and Laserra, E. (2004) Fantappiè's Group as an Extension of Special Relativity on $\varepsilon(\infty)$ Cantorian Space-Time. Chaos, Solitons \& Fractals, 22, 975-983. https://doi.org/10.1016/j.chaos.2004.04.019

[209] El Naschie, M.S. (2015) A Casimir-Dark Energy Nano Reactor Design-Phase One. Natural Science, 7, 287. https://doi.org/10.4236/ns.2015.76032

[210] Ord, G.N. (1997) Classical Particles and the Dirac Equation with an Electromagnetic Field. 
Chaos, Solitons \& Fractals, 8, 727-741. https://doi.org/10.1016/S0960-0779(96)00059-8

[211] Agop, M., Paun, V. and Harabagiu, A. (2008) El Naschie's $\varepsilon(\infty)$ Theory and Effects of Nanoparticle Clustering on the Heat Transport in Nanofluids. Chaos, Solitons \& Fractals, 37, 1269-1278. https://doi.org/10.1016/j.chaos.2008.01.006

[212] El Naschie, M.S., Marek-Crnjac, L., He, J.H. and Helal, M.A. (2013) Computing the Missing Dark Energy of a Clopen Universe Which Is Its Own Multiverse in Addition to Being Both Flat and Curved. Fractal Spacetime and Noncommutative Geometry in Quantum and High Energy Physics, 3, 3-10.

[213] El Naschie, M.S. (2005) A Tale of Two Kleins Unified in Strings and E-Infinity Theory. Chaos, Solitons \& Fractals, 26, 247-254. https://doi.org/10.1016/j.chaos.2005.01.016

[214] Nottale, L. (2005) On the Transition from the Classical to the Quantum Regime in Fractal Space-Time Theory. Chaos, Solitons \& Fractals, 25, 797-803. https://doi.org/10.1016/j.chaos.2004.11.071

[215] El Naschie, M.S. (2007) Rigorous Derivation of the Inverse Electromagnetic Fine Structure Constant Using Super String Theory and the Holographic Boundary of E-Infinity. Chaos, Solitons \& Fractals, 32, 893-895. https://doi.org/10.1016/j.chaos.2006.09.055

[216] Saniga, M. (2001) Cremona Transformations and the Conundrum of Dimensionality and Signature of Macro-Spacetime. Chaos, Solitons \& Fractals, 12, 2127-2142. https://doi.org/10.1016/S0960-0779(00)00183-1

[217] El Naschie, M.S. (1995) Quantum Measurement, Information, Diffusion and Cantorian Geodesies. Quantum Mechanics, Diffusion and Chaotic Fractals, Pergamon Press, Oxford.

[218] Mejias, A., Sigalotti, L.D.G., Sira, E. and De Felice, F. (2004) On El Naschie's Complex Time, Hawking's Imaginary Time and Special Relativity. Chaos, Solitons \& Fractals, 19, 773-777. https://doi.org/10.1016/S0960-0779(03)00273-X

[219] Munceleanu, G.V., Paun, V.P., Casian-Botez, I. and Agop, M. (2011) The MicroscopicMacroscopic Scale Transformation through a Chaos Scenario in the Fractal Space-Time Theory. International Journal of Bifurcation and Chaos in Applied Sciences and Engineering, 21, 603. https://doi.org/10.1142/S021812741102888X

[220] Ho, M.E.N. and Giuseppe Vitiello, M.W. (2015) Is Spacetime Fractal and Quantum Coherent in the Golden Mean? Global Journal of Science Frontier Research, 15.

[221] El Naschie, M.S. (2003) The Cantorian Interpretation of High Energy Physics and the Mass Spectrum of Elementary Particles. Chaos, Solitons \& Fractals, 17, 989-1001. https://doi.org/10.1016/S0960-0779(03)00006-7

[222] El Naschie, M.S. (2006) Thomas Mann and Heinrich Mann, Dual Brothers and Complimentary Genius Embraced by Complex Reality. International Journal of Nonlinear Sciences and Numerical Simulation, 7, 1-6. https://doi.org/10.1515/IJNSNS.2006.7.1.1

[223] Castro, C., Granik, A. and El Naschie, M.S. (2000) Why We Live in 3 Dimensions. arXiv Preprint hep-th/0004152.

[224] Selvam, A.M. (2005) A General Systems Theory for Chaos, Quantum Mechanics and Gravity for Dynamical Systems of All Space-Time Scales. arXiv Preprint Physics/0503028.

[225] Iovane, G. and Benedetto, E. (2006) A Projective Approach to Dynamical Systems, Applications in Cosmology and Connections with El Naschie $\epsilon(\infty)$ Cantorian Space-Time. Chaos, Solitons \& Fractals, 30, 269-277. https://doi.org/10.1016/j.chaos.2005.11.005

[226] Goldfain, E. (2005) Local Scale Invariance, Cantorian Space-Time and Unified Field Theory. Chaos, Solitons \& Fractals, 23, 701-710. https://doi.org/10.1016/j.chaos.2004.05.020

[227] El Naschie, M.S. (2016) On a Quantum Gravity Fractal Spacetime Equation: QRG $\simeq$ HD + 
FG and Its Application to Dark Energy-Accelerated Cosmic Expansion. Journal of Modern Physics, 7, 729. https://doi.org/10.4236/jmp.2016.78069

[228] El Naschie, M.S. (2007) Deterministic Quantum Mechanics versus Classical Mechanical Indeterminism. International Journal of Nonlinear Sciences and Numerical Simulation, 8, 5-10. https://doi.org/10.1515/IJNSNS.2007.8.1.5

[229] El Naschie, M.S. (2009) Arguments for the Compactness and Multiple Connectivity of Our Cosmic Spacetime. Chaos, Solitons \& Fractals, 41, 2787-2789. https://doi.org/10.1016/j.chaos.2008.10.011

[230] El Naschie, M.S. (2016) Negative Norms in Quantized Strings as Dark Energy Density of the Cosmos. World Journal of Condensed Matter Physics, 6, 63. https://doi.org/10.4236/wjcmp.2016.62009

[231] El Naschie, M.S. (2015) The Casimir Effect as a Pure Topological Phenomenon and the Possibility of a Casimir Nano Reactor-A Preliminary Conceptual Design. American Journal of Nano Research and Applications, 3, 33-40.

[232] El Naschie, M.S. (2000) Scale Relativity in Cantorian E ( $\infty$ ) Space-Time. Chaos, Solitons \& Fractals, 11, 2391-2395. https://doi.org/10.1016/S0960-0779(99)00209-X

[233] Stakhov, A. and Rozin, B. (2005) The Golden Shofar. Chaos, Solitons \& Fractals, 26, 677684. https://doi.org/10.1016/j.chaos.2005.01.057

[234] He, J.H. (2009) Hilbert Cube Model for Fractal Spacetime. Chaos, Solitons \& Fractals, 42, 2754-2759. https://doi.org/10.1016/j.chaos.2009.03.182

[235] El Naschie, M.S. (2016) Einstein's Dark Energy via Similarity Equivalence, 'tHooft Dimensional Regularization and Lie Symmetry Groups. International Journal of Astronomy and Astrophysics, 6, 56. https://doi.org/10.4236/ijaa.2016.61005

[236] El Naschie, M.S. (2005) A Few Hints and Some Theorems about Witten's M Theory and T-Duality. Chaos, Solitons \& Fractals, 25, 545-548. https://doi.org/10.1016/j.chaos.2005.01.009

[237] Sidharth, B.G. (2003) The New Cosmos. Chaos, Solitons \& Fractals, 18, 197-201. https://doi.org/10.1016/S0960-0779(02)00632-X

[238] El Naschie, M.S. (2004) The Higgs-Physical and Number Theoretical Arguments for the Necessity of a Triple Elementary Particle in Super Symmetric Spacetime. Chaos, Solitons \& Fractals, 22, 1199-1209. https://doi.org/10.1016/j.chaos.2004.04.026

[239] El Naschie, M.S. (1999) From Implosion to Fractal Spheres: A Brief Account of the Historical Development of Scientific Ideas Leading to the Trinity Test and beyond. Chaos, Solitons \& Fractals, 10, 1955-1965. https://doi.org/10.1016/S0960-0779(99)00030-2

[240] Dariescu, M.A., Dariescu, C. and Pîrghie, A.C. (2009) Mass Spectrum in 5D Warped Einstein Universe and El Naschie's Quantum Golden Field Theory. Chaos, Solitons \& Fractals, 42, 247-252. https://doi.org/10.1016/j.chaos.2008.11.021

[241] Maker, D. (1999) Quantum Physics and Fractal Space Time. Chaos, Solitons \& Fractals, 10, 31-42. https://doi.org/10.1016/S0960-0779(98)00108-8

[242] El Naschie, M.S. (2008) Using Witten's Five Brane Theory and the Holographic Principle to Derive the Value of the Electromagnetic Fine Structure Constant. Chaos, Solitons \& Fractals, 38, 1051-1053. https://doi.org/10.1016/j.chaos.2008.06.001

[243] Iovane, G., Laserra, E. and Giordano, P. (2004) Fractal Cantorian Structures with Spatial Pseudo-Spherical Symmetry for a Possible Description of the Actual Segregated Universe as a Consequence of Its Primordial Fluctuations. Chaos, Solitons \& Fractals, 22, 521-528. https://doi.org/10.1016/j.chaos.2004.02.026 
[244] He, J.H. and Xu, L. (2009) Number of Elementary Particles Using Exceptional Lie Symmetry Groups Hierarchy. Chaos, Solitons \& Fractals, 39, 2119-2124.

https://doi.org/10.1016/j.chaos.2007.06.088

[245] Naschie, M.E. (2006) The "Discreet" Charm of Certain Eleven Dimensional Spacetime Theories. International Journal of Nonlinear Sciences and Numerical Simulation, 7, 477482. https://doi.org/10.1515/IJNSNS.2006.7.4.477

[246] Auffray, J.P. (2014) E-Infinity Dualities, Discontinuous Spacetimes, Xonic Quantum Physics and the Decisive Experiment. Journal of Modern Physics, 5, 1427. https://doi.org/10.4236/jmp.2014.515144

[247] El Naschie, M.S. (2015) A Fractal Rindler-Regge Triangulation in the Hyperbolic Plane and Cosmic de Sitter Accelerated Expansion. Journal of Quantum Information Science, 5, 24. https://doi.org/10.4236/jqis.2015.51004

[248] El Naschie, M.S. (2006) Holographic Correspondence and Quantum Gravity in E-Infinity Spacetime. Chaos, Solitons \& Fractals, 29, 871-875. https://doi.org/10.1016/j.chaos.2006.01.005

[249] Greene, B. (2004) The Fabric of the Cosmos. Penguin Books, London.

[250] El Naschie, M.S. (2016) From Witten's 462 Supercharges of 5-D Branes in Eleven Dimensions to the 95.5 Percent Cosmic Dark Energy Density behind the Accelerated Expansion of the Universe. Journal of Quantum Information Science, 6, 57. https://doi.org/10.4236/jqis.2016.62007

[251] El-Ahmady, A.E. and Al-Hesiny, E. (2011) The Topological Folding of the Hyperbola in Minkowski 3-Space. The International Journal of Nonlinear Science, 11, 451-458.

[252] Iovane, G. (2004) Varying G, Accelerating Universe, and Other Relevant Consequences of a Stochastic Self-Similar and Fractal Universe. Chaos, Solitons \& Fractals, 20, 657-667. https://doi.org/10.1016/j.chaos.2003.09.036

[253] El Naschie, M.S. (2005) Spinorial Content of the Standard Model, a Different Look at Super-Symmetry and Fuzzy E-Infinity Hyper Kähler. Chaos, Solitons \& Fractals, 26, 303-311. https://doi.org/10.1016/j.chaos.2005.03.004

[254] El Naschie, M.S. (2015) The Counterintuitive Increase of Information Due to Extra Spacetime Dimensions of a Black Hole and Dvoretzky's Theorem. Natural Science, 7, 483. https://doi.org/10.4236/ns.2015.710049

[255] Marek-Crnjac, L. (2003) The Mass Spectrum of High Energy Elementary Particles via El Naschie's E $(\infty)$ Golden Mean Nested Oscillators, the Dunkerly-Southwell Eigenvalue Theorems and KAM. Chaos, Solitons \& Fractals, 18, 125-133. https://doi.org/10.1016/S0960-0779(02)00587-8

[256] Marek-Crnjac, L. (2009) Partially Ordered Sets, Transfinite Topology and the Dimension of Cantorian-Fractal Spacetime. Chaos, Solitons \& Fractals, 42, 1796-1799. https://doi.org/10.1016/j.chaos.2009.03.094

[257] Özgür, C. (2009) On Some Classes of Super Quasi-Einstein Manifolds. Chaos, Solitons \& Fractals, 40, 1156-1161. https://doi.org/10.1016/j.chaos.2007.08.070

[258] Sidharth, B.G. (2002) Quantum Superstrings and Quantized Fractal Space-Time. Chaos, Solitons \& Fractals, 13, 189-193. https://doi.org/10.1016/S0960-0779(00)00269-1

[259] Iovane, G. (2006) Cantorian Space-Time, Fantappie’s Final Group, Accelerated Universe and Other Consequences. Chaos, Solitons \& Fractals, 27, 618-629. https://doi.org/10.1016/j.chaos.2005.04.093

[260] El Naschie, M.S. (2008) The Exceptional Eightfold Way to a Possible Higgs Field. Chaos, Solitons \& Fractals, 35, 664-667. https://doi.org/10.1016/j.chaos.2007.07.082 
[261] Tanaka, Y., Mizuno, Y. and Kado, T. (2005) Chaotic Dynamics in the Friedmann Equation. Chaos, Solitons \& Fractals, 24, 407-422. https://doi.org/10.1016/j.chaos.2004.09.034

[262] Auffray, J.P. (2015) E Infinity, the Zero Set, Absolute Space and the Photon Spin. Journal of Modern Physics, 6, 536. https://doi.org/10.4236/jmp.2015.65058

[263] Martienssen, W. (2005) Mohamed El Naschie and the Geometrical Interpretation of Quantum Physics. Chaos, Solitons \& Fractals, 25, 805-806. https://doi.org/10.1016/j.chaos.2005.02.001

[264] Agop, M. and Vasilica, M. (2006) El Naschie's Supergravity by Means of the Gravitational Instantons Synchronization. Chaos, Solitons \& Fractals, 30, 318-323. https://doi.org/10.1016/j.chaos.2006.01.105

[265] Chen, Q. and Shi, Z. (2008) Biorthogonal Multiple Vector-Valued Multivariate Wavelet Packets Associated with a Dilation Matrix. Chaos, Solitons \& Fractals, 35, 323-332. https://doi.org/10.1016/j.chaos.2007.06.065

[266] Qiu, H. and Su, W. (2007) 3-Adic Cantor Function on Local Fields and Its p-Adic Derivative. Chaos, Solitons \& Fractals, 33, 1625-1634. https://doi.org/10.1016/j.chaos.2006.03.024

[267] Nottale, L. (2001) Relativitéd' échelle structure de la théorie. Revue de Synthèse, 122, 11-25. https://doi.org/10.1007/BF02990499

[268] El Naschie, M.S. (2003) Complex Vacuum Fluctuation as a Chaotic "Limit" Set of Any Kleinian Group Transformation and the Mass Spectrum of High Energy Particle Physics via Spontaneous Self-Organization. Chaos, Solitons \& Fractals, 17, 631-638. https://doi.org/10.1016/S0960-0779(02)00630-6

[269] Vrobel, S. (2011) Why a Watched Kettle Never Boils.

[270] Gottlieb, I., Ciobanu, G. and Buzea, C.G. (2003) El Naschie’s Cantorian Space Time, Toda Lattices and Cooper-Agop Pairs. Chaos, Solitons \& Fractals, 17, 789-796. https://doi.org/10.1016/S0960-0779(02)00484-8

[271] He, J.H. (2009) Nonlinear Science as a Fluctuating Research Frontier. Chaos, Solitons \& Fractals, 41, 2533-2537. https://doi.org/10.1016/j.chaos.2008.09.027

[272] Argyris, J., Ciubotariu, C.I. and Weingaertner, W.E. (2000) Fractal Space Signatures in Quantum Physics and Cosmology-I. Space, Time, Matter, Fields and Gravitation. Chaos, Solitons \& Fractals, 11, 1671-1719. https://doi.org/10.1016/S0960-0779(99)00065-X

[273] El Naschie, M.S. (2007) From Pointillism to E-Infinity Electromagnetism. Chaos, Solitons \& Fractals, 34, 1377-1381. https://doi.org/10.1016/j.chaos.2007.02.016

[274] Agop, M. and Craciun, P. (2006) El Naschie's Cantorian Gravity and Einstein's Quantum Gravity. Chaos, Solitons \& Fractals, 30, 30-40. https://doi.org/10.1016/j.chaos.2006.01.006

[275] Agop, M., Ioannou, P.D. and Buzea, C.G. (2002) Cantorian E ( $\infty$ ) Space-Time, Gravitation and Superconductivity. Chaos, Solitons \& Fractals, 13, 1137-1165. https://doi.org/10.1016/S0960-0779(01)00123-0

[276] Sidharth, B.G. (2001) A Reconciliation of Electromagnetism and Gravitation. arXiv Preprint Physics/0110040.

[277] El-Nabulsi, A.R. (2009) Fractional Nottale's Scale Relativity and Emergence of Complexified Gravity. Chaos, Solitons \& Fractals, 42, 2924-2933. https://doi.org/10.1016/j.chaos.2009.04.004

[278] Weiss, H. and Weiss, V. (2003) The Golden Mean as Clock Cycle of Brain Waves. Chaos, Solitons \& Fractals, 18, 643-652. https://doi.org/10.1016/S0960-0779(03)00026-2

[279] Wu, G.C. and He, J.H. (2009) On the Menger-Urysohn Theory of Cantorian Manifolds and Transfinite Dimensions in Physics. Chaos, Solitons \& Fractals, 42, 781-783. 
https://doi.org/10.1016/j.chaos.2009.02.007

[280] Czajko, J. (2004) On Cantorian Spacetime over Number Systems with Division by Zero. Chaos, Solitons \& Fractals, 21, 261-271. https://doi.org/10.1016/j.chaos.2003.12.046

[281] Sidharth, B.G. (2002) Consequences of a Quantized Space-Time Model. Chaos, Solitons \& Fractals, 13, 617-620. https://doi.org/10.1016/S0960-0779(01)00017-0

[282] De, A., De, U.C. and Gazi, A.K. (2011) On a Class of N( $\kappa)$-Quasi Einstein Manifolds. Communications of the Korean Mathematical Society, 26, 623-634. https://doi.org/10.4134/CKMS.2011.26.4.623

[283] El Naschie, M.S. (2008) Asymptotic Freedom and Unification in a Golden Quantum Field Theory. Chaos, Solitons \& Fractals, 36, 521-525. https://doi.org/10.1016/j.chaos.2007.09.004

[284] Sidharth, B.G. (2000) Quantized Space-Time and Time’s Arrow. Chaos, Solitons \& Fractals, 11, 1045-1046. https://doi.org/10.1016/S0960-0779(98)00331-2

[285] El Naschie, M.S. (2001) The Exact Value of the Smallest Quantum Gravity Coupling Constant is $1 / \alpha \mathrm{g}=42.36067977$. Chaos, Solitons \& Fractals, 12, 1361-1368. https://doi.org/10.1016/S0960-0779(01)00008-X

[286] Iovane, G., Laserra, E. and Tortoriello, F.S. (2004) Stochastic Self-Similar and Fractal Universe. Chaos, Solitons \& Fractals, 20, 415-426. https://doi.org/10.1016/j.chaos.2003.08.004

[287] Saniga, M. (2002) Onspatially Anisotropic' Pencil-Space-Times Associated with a QuadroCubic Cremona Transformation. Chaos, Solitons \& Fractals, 13, 807-814. https://doi.org/10.1016/S0960-0779(01)00056-X

[288] Nottale, L. (2001) Scale Relativity and Gauge Invariance. Chaos, Solitons \& Fractals, 12, 1577-1583. https://doi.org/10.1016/S0960-0779(01)00015-7

[289] El Naschie, M.S. (2008) Quarks Confinement. Chaos, Solitons \& Fractals, 37, 6-8. https://doi.org/10.1016/j.chaos.2007.09.057

[290] El Naschie, M.S., Olsen, S. and He, J.H. (2013) Dark Energy of the Quantum HawkingHartle Wave of the Cosmos from the Holographic Boundary and Lie Symmetry GroupsExact Computation and Physical Interpretation. Fractal Spacetime and Noncommutative Geometry, 3, 11-20.

[291] El Naschie, M.S. (1997) Introduction to Nonlinear Dynamics, General Relativity and the Quantum: The Uneven Flow of Fractal Time. Chaos, Solitons \& Fractals, 8, vii-x. https://doi.org/10.1016/S0960-0779(97)83767-8

[292] El Naschie, M.S. (2004) On the Possibility of Two New "Elementary" Particles with Mass Equal to $\mathrm{m}(\mathrm{k})=1.80339 \mathrm{MeV}$ and $\mathrm{m}(\overline{\alpha g s})=26.180339 \mathrm{MeV}$. Chaos, Solitons \& Fractals, 20, 649-654. https://doi.org/10.1016/j.chaos.2003.10.010

[293] Xu, L. and Zhong, T. (2011) Golden Ratio in Quantum Mechanics. Nonlinear Science Letters $B, 1,10-11$.

[294] Giordano, P. (2006) Numerical Analysis of Hypersingular Integral Equations in the E-Infinite Cantorian Spacetime. International Journal of Nonlinear Sciences and Numerical Simulation, 7, 451-460.

[295] Nozari, K. and Mehdipour, S.H. (2009) Failure of Standard Thermodynamics in Planck Scale Black Hole System. Chaos, Solitons \& Fractals, 39, 956-970. https://doi.org/10.1016/j.chaos.2007.02.018

[296] Benedetto, E. (2009) Fantappié-Arcidiacono Spacetime and Its Consequences in Quantum Cosmology. International Journal of Theoretical Physics, 48, 1603-1621. https://doi.org/10.1007/s10773-009-9933-0

[297] El Naschie, M.S. (2007) A Derivation of the Electromagnetic Coupling $\alpha_{0} \simeq 137.036$. Chaos, 
Solitons \& Fractals, 31, 521-526. https://doi.org/10.1016/j.chaos.2006.06.028

[298] Zmeskal, O., Nezadal, M. and Buchnicek, M. (2003) Fractal-Cantorian Geometry, Hausdorff Dimension and the Fundamental Laws of Physics. Chaos, Solitons \& Fractals, 17, $113-$ 119. https://doi.org/10.1016/S0960-0779(02)00412-5

[299] Castro, C. (2000) On the Four Dimensional Conformal Anomaly, Fractal Spacetime and the Fine Structure Constant. arXiv Preprint Physics/0010072.

[300] Marek-Crnjac, L. (2008) From Arthur Cayley via Felix Klein, Sophus Lie, Wilhelm Killing, Elie Cartan, Emmy Noether and Superstrings to Cantorian Space-Time. Chaos, Solitons \& Fractals, 37, 1279-1288. https://doi.org/10.1016/j.chaos.2008.01.021

[301] Özgür, C. (2009) Hypersurfaces Satisfying Some Curvature Conditions in the Semi-Euclidean Space. Chaos, Solitons \& Fractals, 39, 2457-2464.

https://doi.org/10.1016/j.chaos.2007.07.018

[302] Sidharth, B.G. (2001) The Unification of Electromagnetism and Gravitation in the Context of Quantized Fractal Space-Time. Chaos, Solitons \& Fractals, 12, 2143-2147. https://doi.org/10.1016/S0960-0779(00)00181-8

[303] Fred, Y.Y. (2009) From Chaos to Unification: U Theory vs. M Theory. Chaos, Solitons \& Fractals, 42, 89-93. https://doi.org/10.1016/j.chaos.2008.10.030

[304] Colotin, M., Pompilian, G.O., Nica, P., Gurlui, S., Paun, V. and Agop, M. (2009) Fractal Transport Phenomena through the Scale Relativity Model. Acta Physica Polonica, Series A General Physics, 116, 157. https://doi.org/10.12693/APhysPolA.116.157

[305] Rossler, O.E., Fröhlich, D., Movassagh, R. and Moore, A. (2007) Hubble Expansion in Static Spacetime. Chaos, Solitons \& Fractals, 33, 770-775.

https://doi.org/10.1016/j.chaos.2006.06.046

[306] El Naschie, M.S. (2004) Anomalous Positron Peaks and Experimental Verification of $\varepsilon(\infty)$ Super Symmetric Grand Unification. Chaos, Solitons \& Fractals, 20, 455-458.

https://doi.org/10.1016/j.chaos.2003.10.008

[307] Agop, M., Ioannou, P.D., Nica, P., Buzea, C.G. and Jarcau, M. (2003) $\varepsilon(\infty)$ Cantorian Space-Time, Polarization Gravitational Field and van der Waals-Type Forces. Chaos, Solitons \& Fractals, 18, 1-16. https://doi.org/10.1016/S0960-0779(02)00633-1

[308] Agop, M., Ciobanu, G. and Zaharia, L. (2003) Cantorian E ( $\infty$ ) Space-Time, Frames and Unitary Theories. Chaos, Solitons \& Fractals, 15, 445-453. https://doi.org/10.1016/S0960-0779(02)00139-X

[309] Rami, E.N.A. (2009) Fractional Dynamics, Fractional Weak Bosons Masses and Physics beyond the Standard Model. Chaos, Solitons \& Fractals, 41, 2262-2270. https://doi.org/10.1016/j.chaos.2008.08.033

[310] Zmeskal, O., Vala, M., Weiter, M. and Stefkova, P. (2009) Fractal-Cantorian Geometry of Space-Time. Chaos, Solitons \& Fractals, 42, 1878-1892. https://doi.org/10.1016/j.chaos.2009.03.106

[311] Iovane, G., Bellucci, S. and Benedetto, E. (2008) Projected Space-Time and Varying Speed of Light. Chaos, Solitons \& Fractals, 37, 49-59. https://doi.org/10.1016/j.chaos.2007.09.022

[312] Goldfain, E. (2005) Higgs-Free Derivation of Gauge Boson Masses Using Complex Dynamics of Levy Flows. International Journal of Nonlinear Sciences and Numerical Simulation, 6, 351-356. https://doi.org/10.1515/IJNSNS.2005.6.4.351

[313] deFelice, F., Sigalotti, L.D.G. and Mejias, A. (2004) Lorentz Transformations and Complex Space-Time Functions. Chaos, Solitons \& Fractals, 21, 573-578. https://doi.org/10.1016/j.chaos.2003.12.091 
[314] El Naschie, M.S. (2005) Supergravity and the Number of Fundamental Particles in the Standard Model. Chaos, Solitons \& Fractals, 23, 1941-1943. https://doi.org/10.1016/j.chaos.2004.08.005

[315] Elokaby, A. (2009) Knot Wormholes and the Dimensional Invariant of Exceptional Lie Groups and Stein Space Hierarchies. Chaos, Solitons \& Fractals, 41, 1616-1618. https://doi.org/10.1016/j.chaos.2008.07.003

[316] Nottale, L. (2000) Scale Relativity, Fractal Space-Time and Morphogenesis of Structures. Sciences of the Interface, Sciences of the Interface. Proceedings of International Symposium in Honor of O. Rössler, ZKM Karlruhe, Genista, Tübingen, 38.

[317] Agop, M., Ioannou, P.D., Buzea, C. and Nica, P. (2003) Cantorian $\varepsilon(\infty)$ Space-Time, a Hydrodynamical Model and Unified Superconductivity. Chaos, Solitons \& Fractals, 16, 321 338. https://doi.org/10.1016/S0960-0779(02)00413-7

[318] Rami, E.N.A. (2009) Fractional Illusion Theory of Space: Fractional Gravitational Field with Fractional Extra-Dimensions. Chaos, Solitons \& Fractals, 42, 377-384. https://doi.org/10.1016/j.chaos.2008.12.008

[319] El Naschie, M.S. (2000) On the Unification of Heterotic Strings, M Theory and E $(\infty)$ Theory. Chaos, Solitons \& Fractals, 11, 2397-2408. https://doi.org/10.1016/S0960-0779(00)00108-9

[320] El Naschie, M.S. and He, J.H. (2013) Quantum Gravity and Dark Energy via a New Planck Scale. Fractal Spacetime and Noncommutative Geometry in Quantum and High Energy Physics, 3, 106-119.

[321] Dickau, J.J. (2009) Fractal Cosmology. Chaos, Solitons \& Fractals, 41, 2103-2105. https://doi.org/10.1016/j.chaos.2008.07.056

[322] El Naschie, M.S. (2008) Roots Lattice Hierarchies of Exceptional Lie Symmetry Groups and the Elementary Particles Content of the Standard Model. Chaos, Solitons \& Fractals, 35, 684-687. https://doi.org/10.1016/j.chaos.2007.07.084

[323] Tomaschitz, R. (1997) Chaos and Topological Evolution in Cosmology. International Journal of Bifurcation and Chaos, 7, 1847-1853. https://doi.org/10.1142/S0218127497001412

[324] Ho, M.W. (2014) E-Infinity Spacetime, Quantum Paradoxes and Quantum Gravity. Journal of the Institute of Science in Society, 62, 40-43.

[325] Sidharth, B.G. (2003) A Note on the Modified Uncertainity Principle. Chaos, Solitons \& Fractals, 15, 593-595. https://doi.org/10.1016/S0960-0779(02)00159-5

[326] Ćirić, L.B., Ješić, S.N. and Ume, J.S. (2008) The Existence Theorems for Fixed and Periodic Points of Nonexpansive Mappings in Intuitionistic Fuzzy Metric Spaces. Chaos, Solitons \& Fractals, 37, 781-791. https://doi.org/10.1016/j.chaos.2006.09.093

[327] El Naschie, M.S. (2005) Tadpoles, Anomaly Cancellation and the Expectation Value of the Number of the Higgs Particles in the Standard Model. Chaos, Solitons \& Fractals, 24, 659663. https://doi.org/10.1016/j.chaos.2004.11.002

[328] Yildiz, A., De, U.C. and Cetinkaya, A. (2011) N (k)-Quasi Einstein Manifolds Satisfying Certain Curvature Conditions. Dumlupinar University Research Found (No: 2011-25).

[329] Sidharth, B.G. (2002) A Note on Duality and Scale. Chaos, Solitons \& Fractals, 13, 13691370. https://doi.org/10.1016/S0960-0779(01)00114-X

[330] Tanaka, Y. (2005) Relativistic Field Theory and Chaotic Dynamics. Chaos, Solitons \& Fractals, 23, 33-41. https://doi.org/10.1016/j.chaos.2004.03.031

[331] Nagasawa, M. (1997) On the Locality of Hidden-Variable Theories in Quantum Physics. Chaos, Solitons \& Fractals, 8, 1773-1792. https://doi.org/10.1016/S0960-0779(97)00036-2 
[332] El Naschie, M.S. (2008) String Theory, Exceptional Lie Groups Hierarchy and the Structural Constant of the Universe. Chaos, Solitons \& Fractals, 35, 7-12. https://doi.org/10.1016/j.chaos.2007.06.023

[333] El Naschie, M.S. (2008) On Quarks Confinement and Asymptotic Freedom. Chaos, Solitons \& Fractals, 37, 1289-1291. https://doi.org/10.1016/j.chaos.2008.02.002

[334] El Naschie, M.S. (2009) E-Eight Exceptional Lie Groups, Fibonacci Lattices and the Standard Model. Chaos, Solitons \& Fractals, 41, 1340-1343. https://doi.org/10.1016/j.chaos.2008.05.015

[335] Iovane, G. and Salerno, S. (2005) Dynamical Systems on Cantorian Spacetime and Applications. WSEAS Transactions on Mathematics, 4, 184.

[336] Liu, S.D., Liu, S.K., Fu, Z.T., Ren, K. and Guo, Y. (2003) The Most Intensive Fluctuation in Chaotic Time Series and Relativity Principle. Chaos, Solitons \& Fractals, 15, 627-630. https://doi.org/10.1016/S0960-0779(02)00138-8

[337] Yang, C.D. (2008) On the Existence of Complex Spacetime in Relativistic Quantum Mechanics. Chaos, Solitons \& Fractals, 38, 316-331. https://doi.org/10.1016/j.chaos.2008.01.019

[338] El Naschie, M.S., Olsen, S., He, J.H., Nada, S., Marek-Crnjac, L. and Helal, A. (2012) On the Need for Fractal Logic in High Energy Quantum Physics. International Journal of Modern Nonlinear Theory and Application, 1, Article ID: 23087. https://doi.org/10.4236/ijmnta.2012.13012

[339] Marek-Crnjac, L. (2006) Different Higgs Models and the Number of Higgs Particles. Chaos, Solitons \& Fractals, 27, 575-579. https://doi.org/10.1016/j.chaos.2005.04.099

[340] Pavlos, G.P., Iliopoulos, A.C., Karakatsanis, L.P., Tsoutsouras, V.G. and Pavlos, E.G. (2011) Complexity Theory and Physical Unification: From Microscopic to Macroscopic Level. Chaos Theory: Modeling, Simulation and Applications. World Scientific Publishing, 297308. https://doi.org/10.1142/9789814350341_0035

[341] El Naschie, M.S. (1993) Semiconductors, Fermi Statistics and Multi-Dimensional Cantor Sets. Chaos, Solitons \& Fractals, 3, 481-488. https://doi.org/10.1016/0960-0779(93)90032-V

[342] Gottlieb, I. and Agop, M. (2007) El Naschie's $\varepsilon(\infty)$ Theory and an Alternative to Gauged Spacetime Scale Relativity Theory. Chaos, Solitons \& Fractals, 34, 1025-1029. https://doi.org/10.1016/j.chaos.2006.03.108

[343] El Naschie, M.S. (2013) Electromagnetic and Gravitational Origin of Dark Energy in Kaluza-Klein D = 5 Spacetime. PIERS Proceeding, Stockholm, Sweden, 91-97.

[344] Sigalotti, L.D.G. and Rendón, O. (2007) Quantum Decoherence and El Naschie's Complex Temporality. Chaos, Solitons \& Fractals, 32, 1611-1614. https://doi.org/10.1016/j.chaos.2006.08.034

[345] Ord, G.N. (1996) The Schrödinger and Diffusion Propagators Coexisting on a Lattice. Journal of Physics A: Mathematical and General, 29, L123. https://doi.org/10.1088/0305-4470/29/5/007

[346] Saniga, M. (2005) Cremonian Space-Time (s) as an Emergent Phenomenon. Chaos, Solitons \& Fractals, 23, 645-650. https://doi.org/10.1016/j.chaos.2004.05.018

[347] El Naschie, M.S. (2016) High Energy Physics and Cosmology as Computation. American Journal of Computational Mathematics, 6, 185. https://doi.org/10.4236/ajcm.2016.63020

[348] El Naschie, M.S. (1996) Wick Rotation, Cantorian Spaces and the Complex Arrow of Time in Quantum Physics. Chaos, Solitons \& Fractals, 7, 1501-1506.

https://doi.org/10.1016/0960-0779(96)80001-B 
[349] Rossler, O.E. and Kuypers, H. (2005) The Scale Change of Einstein's Equivalence Principle. Chaos, Solitons \& Fractals, 25, 897-899. https://doi.org/10.1016/j.chaos.2004.11.097

[350] El Naschie, M.S. (2016) The Emergence of Spacetime from the Quantum in Three Steps. Advances in Pure Mathematics, 6, 446. https://doi.org/10.4236/apm.2016.66032

[351] El Naschie, M.S. (2013) Using Varying Speed of Light Theory to Elucidate and Calculate the Exact Experimental Percentage of the Dark Energy in the Cosmos. Fractal Spacetime and Noncommutative Geometry in Quantum and High Energy Physics, 3, 35-38.

[352] El Naschie, M.S. (2008) The Standard Model Physical Degrees of Freedom Interpretation of the Electromagnetic Fine Structure Coupling. Chaos, Solitons \& Fractals, 38, 609-611. https://doi.org/10.1016/j.chaos.2008.04.015

[353] He, J.H., Zhong, T., Xu, L., Marek-Crnjac, L., Nada, S.I. and Helal, M.A. (2011) The Importance of the Empty Set and Noncommutative Geometry in Underpinning the Foundations of Quantum Physics. Nonlinear Science Letters B, 1, 15-24.

[354] El Naschie, M.S. (2008) Derivation of Newton's Gravitational Fine Structure Constant from the Spectrum of Heterotic Superstring Theory. Chaos, Solitons \& Fractals, 35, 303-307. https://doi.org/10.1016/j.chaos.2007.07.025

[355] Agop, M. and Enache, V. (2007) Gauge Theories on El Naschie's $\varepsilon(\infty)$ Space-Time Topology. Chaos, Solitons \& Fractals, 32, 296-301. https://doi.org/10.1016/j.chaos.2006.04.068

[356] Ho, M.W. (2014) Golden Geometry of E-Infinity Fractal Spacetime. The Story of Phi Part 5.

[357] Agop, M. and Craciun, P. (2006) El Naschie's $\varepsilon(\infty)$ Space-Time and the Two Slit Experiment in the Weyl-Dirac Theory. Chaos, Solitons \& Fractals, 30, 441-452. https://doi.org/10.1016/j.chaos.2005.12.048

[358] El Naschie, M.S. (2008) On a Canonical Equation for All Fundamental Interactions. Chaos, Solitons \& Fractals, 36, 1200-1204. https://doi.org/10.1016/j.chaos.2007.09.039

[359] Marek-Crnjac, L. (2012) Quantum Gravity in Cantorian Space-Time. INTECH Open Access Publisher. https://doi.org/10.5772/37232

[360] El Naschie, M.S. (2003) VAK, Vacuum Fluctuation and the Mass Spectrum of High Energy Particle Physics. Chaos, Solitons \& Fractals, 17, 797-807. https://doi.org/10.1016/S0960-0779(02)00684-7

[361] El Naschie, M.S. (2014) The Gap Labelling Integrated Density of States for a Quasi Crystal Universe Is Identical to the Observed 4.5 Percent Ordinary Energy Density of the Cosmos. Natural Science, 6, 1259. https://doi.org/10.4236/ns.2014.616115

[362] Agop, M. and Gottlieb, I. (2006) Gravitation Theory in a Fractal Space-Time. Journal of Mathematical Physics, 47, 53503-53503. https://doi.org/10.1063/1.2196747

[363] Giné, J. (2008) On the Origin of the Deflection of Light. Chaos, Solitons \& Fractals, 35, 1-6. https://doi.org/10.1016/j.chaos.2007.06.097

[364] Auffray, J.P. (2015) On an Intriguing Invention Albert Einstein Made Which Has Gone Unnoticed Hitherto. Journal of Modern Physics, 6, 1478. https://doi.org/10.4236/jmp.2015.611152

[365] Agop, M., Ioannou, P.D., Nica, P., Găluşcă, G. and Ştefan, M. (2005) El Naschie’s Coherence on the Subquantum Medium. Chaos, Solitons \& Fractals, 23, 1497-1509. https://doi.org/10.1016/S0960-0779(04)00439-4

[366] He, J.H. and Huang, Z. (2006) A Novel Model for Allometric Scaling Laws for Different Organs. Chaos, Solitons \& Fractals, 27, 1108-1114. https://doi.org/10.1016/j.chaos.2005.04.082

[367] Iovane, G. (2007) Hypersingular Integral Equations, Kähler Manifolds and Thurston Mir- 
roring Effect in $\epsilon(\infty)$ Cantorian Spacetime. Chaos, Solitons \& Fractals, 31, 1041-1053.

https://doi.org/10.1016/j.chaos.2006.03.109

[368] Argyris, J., Ciubotariu, C. and Andreadis, I. (1998) Complexity in Spacetime and Gravitation I. FromChaos to Superchaos. Chaos, Solitons \& Fractals, 9, 1651-1701.

https://doi.org/10.1016/S0960-0779(97)00193-8

[369] Agop, M., Ioannou, P.D., Luchian, D., Nica, P., Radu, C. and Condurache, D. (2004) El Naschie's Cantorian Strings and Dendritic Morphogenesis. Chaos, Solitons \& Fractals, 21, 515-536. https://doi.org/10.1016/j.chaos.2003.12.053

[370] Rossler, O.E., Fröhlich, D., Kleiner, N., Pfaff, M. and Argyris, J. (2004) On the Possibility of a New Relativistic Contraction Law. Chaos, Solitons \& Fractals, 20, 205-208. https://doi.org/10.1016/S0960-0779(03)00358-8

[371] Agop, M., Ioannou, P.D., Coman, P., Ciobanu, B. and Nica, P. (2001) Cantorian E ( $\infty$ ) Space-Time and Generalized Superconductivity. Chaos, Solitons \& Fractals, 12, 1947-1982. https://doi.org/10.1016/S0960-0779(00)00161-2

[372] Mukhamedov, A.M. (2007) E-Infinity as a Fiber Bundle and Its Thermodynamics. Chaos, Solitons \& Fractals, 33, 717-724. https://doi.org/10.1016/j.chaos.2006.11.016

[373] Harabagiu, A., Niculescu, O., Colotin, M., Bibire, T.D., Gottlieb, I. and Agop, M. (2009) Particle in a Box by Means of a Fractal Hydrodynamic Model. Romanian Reports in Physics, 61, 395-400.

[374] Ord, G.N. (1999) Gravity and the Spiral Model. Chaos, Solitons \& Fractals, 10, 499-512. https://doi.org/10.1016/S0960-0779(98)00255-0

[375] Castro, C. and Granik, A. (2000) How the New Scale Relativity Theory Resolves Some Quantum Paradoxes. Chaos, Solitons \& Fractals, 11, 2167-2178. https://doi.org/10.1016/S0960-0779(00)00027-8

[376] Castro, C. (2002) On the Four-Dimensional Conformal Anomaly, Fractal Cantorian SpaceTime and the Fine Structure Constant. Chaos, Solitons \& Fractals, 13, 203-207. https://doi.org/10.1016/S0960-0779(00)00268-X

[377] Ahmed, N. (2004) Cantorian Small World, Mach's Principle, and the Universal Mass Network. Chaos, Solitons \& Fractals, 21, 773-781. https://doi.org/10.1016/j.chaos.2004.01.013

[378] Sidharth, B.G. (2001) The Substructure of Space-Time and Some Related Issues. Chaos, Solitons \& Fractals, 12, 2357-2361. https://doi.org/10.1016/S0960-0779(00)00182-X

[379] El Naschie, M.S. (2008) A Derivation of the Fine Structure Constant from the Exceptional Lie Group Hierarchy of the Micro Cosmos. Chaos, Solitons \& Fractals, 36, 819-822. https://doi.org/10.1016/j.chaos.2007.09.020

[380] Mills, R. (1984) Space, Time and Quanta. W. H. Freeman, New York, USA.

[381] El Naschie, M.S. (2008) Freudental Magic Square and Its Dimensional Implication for and High Energy Physics. Chaos, Solitons \& Fractals, 36, 546-549. https://doi.org/10.1016/j.chaos.2007.09.017

[382] Fred, Y.Y. (2009) A Clifford-Finslerian Physical Unification and Fractal Dynamics. Chaos, Solitons \& Fractals, 41, 2301-2305. https://doi.org/10.1016/j.chaos.2008.09.004

[383] El-Okaby, A.A. (2008) Exceptional Lie Groups, E-Infinity Theory and Higgs Boson. Chaos, Solitons \& Fractals, 38, 1305-1317. https://doi.org/10.1016/j.chaos.2008.02.034

[384] Sidharth, B. and Altaisky, M.V. (Eds.) (2012) Frontiers of Fundamental Physics 4. Springer Science \& Business Media.

[385] Buzea, C.G., Agop, M., Galusca, G., Vizureanu, P. and Ionita, I. (2007) El Naschie’s Superconductivity in the Time Dependent Ginzburg-Landau Model. Chaos, Solitons \& Fractals, 
34, 1060-1074. https://doi.org/10.1016/j.chaos.2006.03.122

[386] El Naschie, M.S. (2005) A Note on Various Supersymmetric Extensions of the Standard Model of High-Energy Particles and E-Infinity Theory. Chaos, Solitons \& Fractals, 23, 683 688. https://doi.org/10.1016/j.chaos.2004.06.032

[387] Taylor, J.C. (2001) Hidden Unity in Nature’s Laws. Cambridge University Press, Cambridge, UK.

[388] Ahmed, E. and Hegazi, A.S. (2000) On Infinitesimally Deformed Algebra and Fractal Space-Time Theory. Chaos, Solitons \& Fractals, 11, 1759-1761. https://doi.org/10.1016/S0960-0779(99)00082-X

[389] Tomaschitz, R. (1997) Chaos in the Galactic Dynamics. Fractals, 5, 215-220. https://doi.org/10.1142/S0218348X97000206

[390] Castro, C. (2000) The String Uncertainty Relations Follow from the New Relativity Principle. Foundations of Physics, 30, 1301-1316. https://doi.org/10.1023/A:1003640606529

[391] Christianto, V. (2003) The Cantorian Super Fluid Vortex Hypothesis. Apeiron, 10, 231.

[392] Colotin, M., Niculescu, O., Bibire, T.D., Gottlieb, I., Nica, P. and Agop, M. (2009) Fractal Fluids of Conductive Type Behavior through Scale Relativity Theory. Romanian Reports in Physics, 61, 387-394.

[393] Dariescu, C., Dariescu, M.A. and Murariu, G. (2007) TE Modes in Einstein's Universe. Chaos, Solitons \& Fractals, 34, 1030-1036. https://doi.org/10.1016/j.chaos.2006.04.070

[394] Agop, M., Jarcau, M. and Stroe, A. (2005) El Naschie's Instanton by Means of the Schwarzschild's Gravitational Field. Chaos, Solitons \& Fractals, 25, 781-790. https://doi.org/10.1016/j.chaos.2004.12.036

[395] Lorenzi, M.G., Francaviglia, M. and Iovane, G. (2008) The Golden Mean Revisited: From Fidia to the Structure of "Kosmos". APLIMAT-Journal of Applied Mathematics, 1, 109-119.

[396] He, J.H., Liu, Y., Mo, L.F., Wan, Y.Q. and Xu, L. (2008) Electrospunnanofibres and Their Applications. iSmithers, Shawbury, Shrewsbury, Shropshire, UK.

[397] Yildiz, A., De, U.C. and Cetinkaya, A. (2013) On Some Classes of N (k)-Quasi Einstein Manifolds. Proceedings of the National Academy of Sciences, India Section A: Physical Sciences, 83, 239-245. https://doi.org/10.1007/s40010-013-0071-y

[398] Sidharth, B.G. (2002) The Nature of Quantum Space-Time and the Cantorian E ( $\infty$ ) Proposal. Chaos, Solitons \& Fractals, 14, 1325-1330. https://doi.org/10.1016/S0960-0779(02)00085-1

[399] Ord, G.N. and Gualtieri, J.A. (1998) Information Loss in the Continuum Limit and Schrödinger's Equation in an Electromagnetic Field. Biosystems, 46, 21-28. https://doi.org/10.1016/S0303-2647(97)00077-4

[400] Zhong, T. and He, J.H. (2013) Elnaschie's Resolution of the Mystery of Missing Dark Energy of the Cosmos via Quantum Field Theory in Curved Spacetime. Fractal Spacetime and Noncommutative Geometry in Quantum and High Energy Physics, 3, 46-49.

[401] Dariescu, C. and Dariescu, M.A. (2007) TE-Compatible Maxwell Fields in Spatially Closed Friedman-Robertson-Walker Universe. Chaos, Solitons \& Fractals, 32, 8-14. https://doi.org/10.1016/j.chaos.2006.05.042

[402] Sidharth, B.G. (2002) Dimension and Metric. Chaos, Solitons \& Fractals, 14, 525-527. https://doi.org/10.1016/S0960-0779(01)00197-7

[403] Agop, M., Oprea, I., Sandu, C., Vlad, R., Buzea, C.G. and Matsuzawa, H. (2000) Some Properties of the World Crystal in Fractal Spacetime Theory. Australian Journal of Physics, 53, 231-240. 
[404] Castro, C. and Granik, A. (2000) On M Theory, Quantum Paradoxes and the New Relativity. arXiv Preprint Physics/0002019.

[405] El Naschie, M.S. (2005) Kaluza-Klein and Felix Klein: The Stringy Relationship with the Portrait of the Artist as a Young Man. Chaos, Solitons \& Fractals, 25, 911-913. https://doi.org/10.1016/j.chaos.2004.12.002

[406] Meissner, W. (1996) On a Realistic Interpretation of Spontaneous Decay Processes. Chaos, Solitons \& Fractals, 7, 697-709. https://doi.org/10.1016/0960-0779(94)00220-7

[407] Buzea, C.G., Rusu, I., Bulancea, V., Bădărău, G., Păun, V.P. and Agop, M. (2010) The Time Dependent Ginzburg-Landau Equation in Fractal Space-Time. Physics Letters A, 374, 2757 2765. https://doi.org/10.1016/j.physleta.2010.04.044

[408] Cristescu, C.P., Mereu, B., Stan, C. and Agop, M. (2009) Feigenbaum Scenario in the Dynamics of a Metal-Oxide Semiconductor Heterostructure under Harmonic Perturbation. Golden Mean Criticality. Chaos, Solitons \& Fractals, 40, 975-980. https://doi.org/10.1016/j.chaos.2007.08.054

[409] Penrose, R. (2004) The Road to Reality. A Complete Guide to the Laws of the Universe. Jonathan Cape, London.

[410] Green, B. (2004) The Fabric of the Cosmos. Penguin Books, London.

[411] Hawkings, S and Ellis, G. (1973) The Large Scale Structure of Space-time. Cambridge University Press, Cambridge. https://doi.org/10.1017/CBO9780511524646

[412] 'tHooft, G. (1997) In Search of the Ultimate Building Blocks. Cambridge University Press, Cambridge.

[413] Davies, P. (1989) The New Physics. Cambridge University Press, Cambridge.

[414] Halpern, P. (2004) The Great Beyond. John Wiley, New Jersey.

[415] Zeilinger, A. (2003) Einstein’s Schleier. C. H. Beck Verlog, Munchen-Germany.

[416] Crowell, L.B. (2005) Quantum Fluctuations of Spacetime. World Scientific, Singapore. https://doi.org/10.1142/5952

[417] Smolin, L. (2000) Three Roads to Quantum Gravity. Weidenfeld and Nicolson, London.

[418] 'tHooft, G. (1994) Under the Spell of the Gauge Principle. World Scientific, Singapore.

[419] Kaku, M. (2000) Strings, Conformal fields and M-Theory. Springer, New York. https://doi.org/10.1007/978-1-4612-0503-6

[420] Connes, A. (1994) Non-Commutative Geometry. Academic Press, San Diego.

[421] Becker, K., Becker, M. and Schwarz, J. (2007) String Theory and M-Theory. Cambridge University Press, Cambridge.

[422] Green, M., Schwarz, J. and Witten, E. (1987) Superstring Theory. Vol. I and II. Cambridge University Press, Cambridge.

[423] El Naschie, M.S. (2016) Kähler Dark Matter, Dark Energy Cosmic Density and Their Coupling. Journal of Modern Physics, in Press. https://doi.org/10.4236/jmp.2016.714173

[424] Weinberg, S. (1995) The Quantum Theory of Fields. Vol. I, Cambridge University Press, Cambridge. https://doi.org/10.1017/CBO9781139644167

[425] Oriti, D. (Editor) (2009) Approaches to Quantum Gravity. Cambridge University Press, Cambridge.

[426] El Naschie, M.S. (2016) Completing Einstein's Spacetime. Journal of Modern Physics, 7, 1972. https://doi.org/10.4236/jmp.2016.715175

[427] El Naschie, M.S. (2016) The Speed of the Passing of Time as Yet Another Facet of Cosmic Dark Energy. Journal of Modern Physics, 7, 2103. https://doi.org/10.4236/jmp.2016.715184 
[428] Roukema, B.F. (2012) Topological Acceleration in Relativistic Cosmology. arXiv Preprint arXiv:1212.5426.

[429] Ostrowski, J.J., Roukema, B.F. and Buliński, Z.P. (2012) A Relativistic Model of the Topological Acceleration Effect. Classical and Quantum Gravity, 29, 165006.

https://doi.org/10.1088/0264-9381/29/16/165006

[430] Mark, J.J. (2012) Zeno's Paradoxes; the Illusion of Motion. Ancient History Encyclopedia. http://www.ancient.eu/article/60/

Submit or recommend next manuscript to SCIRP and we will provide best service for you:

Accepting pre-submission inquiries through Email, Facebook, LinkedIn, Twitter, etc.

A wide selection of journals (inclusive of 9 subjects, more than 200 journals)

Providing 24-hour high-quality service

User-friendly online submission system

Fair and swift peer-review system

Efficient typesetting and proofreading procedure

Display of the result of downloads and visits, as well as the number of cited articles

Maximum dissemination of your research work

Submit your manuscript at: http://papersubmission.scirp.org/

Or contact ns@scirp.org 